\title{
Noctilucent clouds and the mesospheric water vapour: the past decade
}

\author{
U. von Zahn ${ }^{1}$, G. Baumgarten ${ }^{1}$, U. Berger ${ }^{1}$, J. Fiedler ${ }^{1}$, and P. Hartogh ${ }^{2}$ \\ ${ }^{1}$ Leibniz-Institute of Atmospheric Physics, Kühlungsborn, Germany \\ ${ }^{2}$ Max-Planck-Institute for Solar System Research, Katlenburg-Lindau, Germany \\ Received: 13 April 2004 - Published in Atmos. Chem. Phys. Discuss.: 4 June 2004 \\ Revised: 24 September 2004 - Accepted: 27 November 2004 - Published: 8 December 2004
}

\begin{abstract}
The topic of this paper is the sensitivity of the brightness of noctilucent clouds (NLC) on the ambient water vapour mixing ratio $\mathrm{f}\left(\mathrm{H}_{2} \mathrm{O}\right)$. Firstly, we use state-of-the-art models of NLC layer formation to predict NLC brightness changes in response to changes in the $80 \mathrm{~km}$ mixing ratio $\mathrm{f}\left(\mathrm{H}_{2} \mathrm{O}\right)$ for the two cases of ground-based $532 \mathrm{~nm}$ lidar observations at $69^{\circ} \mathrm{N}$ and for hemispheric satellite SBUV observations at $252 \mathrm{~nm}$ wavelength. In this study, we include a re-evaluation of the sensitivity of NLC brightness to changes in solar Lyman $\alpha$ flux. Secondly, we review observations of episodic changes in $\mathrm{f}\left(\mathrm{H}_{2} \mathrm{O}\right)$ and those in NLC brightness, the former being available since 1992, the latter since 1979. To this review, we add a new series of observations of $\mathrm{f}\left(\mathrm{H}_{2} \mathrm{O}\right)$, performed in the Arctic summer at the ALOMAR observatory. The episodic change exhibited by the Arctic summer means of $\mathrm{f}\left(\mathrm{H}_{2} \mathrm{O}\right)$ turns out to be quite different from all those derived from annual means of $\mathrm{f}\left(\mathrm{H}_{2} \mathrm{O}\right)$. The latter indicate that since 1996 a significant reduction of annually averaged upper mesospheric water vapour has occurred at low, mid, and high latitudes. These decreases of $\mathrm{f}\left(\mathrm{H}_{2} \mathrm{O}\right)$ have been observed over the same time period in which a slow increase of SBUV NLC albedo has occurred. From this scenario and additional arguments we conclude that the cause for the observed long-term increase in NLC albedo remains to be identified. We close with comments on the very different character of decadal variations in NLC brightness and occurrence rate.
\end{abstract}

\section{Introduction}

The brightness of noctilucent clouds (NLC) is observed to exhibit variability on time scales which range at least from minutes to centuries. For the following, we consider in par-

Correspondence to: U. von Zahn

(vonzahn@iap-kborn.de) ticular variations with interannual and up to decadal time scales (to our knowledge, there exists no generally accepted definition of a "long term" time scale). These variations involve both increases and decreases of NLC parameters and those need be neither linear with time nor periodic. They may be best described as "episodic" in character (Randel et al., 2000), which we construe for NLC phenomena as being non-periodic and having time scales of up to 10 years. We consider the sudden appearance of unusual bright NLC and their subsequent disappearance over northern Europe in the years 1885 until about 1890 as a typical episodic event. We also consider NLC and the so-called polar mesospheric clouds (PMC) to be the same geophysical phenomenon.

Our current theoretical understanding of the microphysics and life cycle of NLC particles makes us believe that the brightness of a NLC layer is primarily controlled by the ambient temperature $\mathrm{T}$ and the partial water vapour pressure $\mathrm{p}\left(\mathrm{H}_{2} \mathrm{O}\right)$ to which the layer is exposed. As regards temperature changes, Lübken (2000) has shown that at $69^{\circ} \mathrm{N}$ no changes of temperatures $\mathrm{T}$ on decadal time scales are so far detectable in the mesosphere ("zero trend"). Against this background, it has become common practice (e.g. Thomas et al., 1989, 2004) to make the following assumption: Episodic changes of NLC brightness are produced exclusively by changes in the water vapour mixing ratio in the upper mesosphere. The point to be made in the current paper is, however, that over the past 7 years the average brightness of NLCs as observed by one set of satellite-borne instruments in the Northern hemisphere has shown hardly any significant change while during the same period a significant decrease of upper mesosphere water vapour abundances has occurred. The latter statement needs an important qualification, though. The observational results on upper mesospheric water vapour have been published so far exclusively as annual or sliding means over all data available. Here we will show, however, that if means for separate seasons are considered, the picture changes remarkably. We evaluate in particular the data

(C) 2004 Author(s). This work is licensed under a Creative Commons License. 
on water vapour in the summer Arctic which in fact show increases of water vapour as long as the observation series exist. This allows for the first time to reconcile observed episodic changes of NLC brightness and water vapour in the NLC region with our model predictions of NLC brightness.

Here we will discuss these topics in more detail in the following order:

1. In a first step, we will use atmospheric modelling to make predictions concerning the dependence of NLC brightness on the ambient $\mathrm{H}_{2} \mathrm{O}$ mixing ratio $\mathrm{f}\left(\mathrm{H}_{2} \mathrm{O}\right)$ and solar Lyman $\alpha$ flux.

2. The second step is to review observations of episodic changes in $\mathrm{f}\left(\mathrm{H}_{2} \mathrm{O}\right)$ and those in NLC brightness, the former being available since 1992, the latter since 1979. To this review, we add a new series of observations of $\mathrm{f}\left(\mathrm{H}_{2} \mathrm{O}\right)$, performed in the Arctic summer at the ALOMAR observatory $\left(69^{\circ} \mathrm{N}\right)$.

3. Thirdly, we compare our model predictions for episodic changes of NLC brightness as caused by observed changes of ambient water vapour and solar Lyman $\alpha$ flux with the actually observed changes.

4. In the discussion section, we address in particular the surprising differences in the decadal variations of NLC occurrence rate and of NLC brightness.

\section{Modelling}

2.1 ALOMAR observations of NLC brightness and water vapour

Various aeronomic parameters are in use to quantify the instantaneous brightness of a NLC layer. For ground-based visual observers, the brightness of a NLC has always been an elusive parameter which was characterized at times by sampling into a number of pre-defined categories or brightness classes (e.g. Romejko et al., 2003). In the case of groundbased lidar soundings, the brightness of a NLC is measured by its absolute volume backscatter coefficient and/or the backscatter ratio at the peak of the NLC layer (Hansen et al., 1989; Fiedler et al., 2003; Thayer et al., 2003; Chu et al., 2003). In the case of satellite-based NLC observations, the wavelength, the scattering geometry, the sample volume as well as the temporal and spatial coverage depend on the instruments in use. Hence a number of different parameters have been adopted for quantifying the brightness of a NLC layer. Examples are the slant radiance and vertical optical depth (Donahue et al., 1972), maximum directional albedo (Jensen and Thomas, 1988), integrated directional albedo (Thomas et al., 1991; DeLand et al., 2003; Shettle et al., 2004), volume emission rates in the mid-IR (O'Neil et al., 2001), or the limb scatter ratio (Merkel et al., 2003).
Our expectations on how the brightness of NLC should vary with changes of the mixing ratio of ambient water vapour are "driven" by the results of ever more sophisticated models of the life cycle of NLC particles. For model calculations, the well-defined backscatter geometry and the precise definition of the sample distance and the sample volume of active lidar soundings make lidar data ideal for robust numerical simulations. It is for these reasons that the absolute volume backscatter coefficient $\beta$ and the backscatter ratio (BSR) at the peak of the NLC layer are calculated in case of the COMMA/IAP model (Berger and von Zahn, 2002; von Zahn and Berger, 2003a) and the CARMA model (Rapp et al., 2002), respectively. Either one of these parameters should represent very well the "brightness" of NLC layers and we will use them here synonymously for NLC layer brightness. However, for comparison with satellite observations we make use of the 3-D coverage of the model and calculate an average cloud albedo for the northern hemisphere in the latitude covered by satellite observations.

Concerning the description of water vapour abundances, we note that phase changes of water vapour to ice, such as occurring at the surfaces of NLC particles, depend basically on the partial pressure $\mathrm{p}\left(\mathrm{H}_{2} \mathrm{O}\right)$. Yet, mixing ratios $\mathrm{f}\left(\mathrm{H}_{2} \mathrm{O}\right)$ are "transportable" in chemistry-transport models and they are much less altitude dependent than partial pressures. It is for those reasons that we will deal primarily with mixing ratios $\mathrm{f}\left(\mathrm{H}_{2} \mathrm{O}\right)$. We do so under the assumption that the ambient densities and temperatures, which are required for the conversion from $\mathrm{f}\left(\mathrm{H}_{2} \mathrm{O}\right)$ to $\mathrm{p}\left(\mathrm{H}_{2} \mathrm{O}\right)$ and vice versa, are reasonably well established.

The COMMA/IAP model is a 3-D GCM optimized for studies of NLC aeronomy. It has been described in detail by Berger and von Zahn (2002) and von Zahn and Berger (2003a). It uses Lagrangian transport of individual dust and icy particles on trajectories (multiple particle system with 20 million individual particles) to evaluate the formation, transport and sublimation of NLC particles and layers. Dust and icy particles are modelled in the latitude range from $50^{\circ} \mathrm{N}$ to $90^{\circ} \mathrm{N}$ and altitude range from 78 to $94 \mathrm{~km}$. Condensation nuclei are presumed to exist in altitude and size distributions according to the model of Hunten et al. (1980).

Using the COMMA/IAP model, we have studied the sensitivity of the volume backscatter coefficients $\beta$ at the peak of NLC layers on the mixing ratio of ambient water vapour $\mathrm{f}\left(\mathrm{H}_{2} \mathrm{O}\right)$. To this end, we have calculated the (zonally averaged) profiles of $\beta$ for a number of different initial $\mathrm{H}_{2} \mathrm{O}$ profiles (see Fig. 1). We initialize the model calculation of the NLC layer with our standard $\mathrm{H}_{2} \mathrm{O}$ profile for 21 June having $\mathrm{f}\left(\mathrm{H}_{2} \mathrm{O}\right)=4.3 \mathrm{ppm}$ at $80 \mathrm{~km}$ as shown in Fig. $4 \mathrm{a}$ of von Zahn and Berger (2003a). With the COMMA/IAP model we follow the development of the NLC layer and its interaction with the upper mesosphere water vapour from the time of initialization up to +5 days. At that time, the water vapour distribution has assumed a new quasi-steady state as shown in Fig. 9a of von Zahn and Berger (2003a) and the 
profile of the volume backscatter coefficient $\beta(\mathrm{z})$ has stabilized its shape and absolute value $\beta_{\max }$ at the peak of the layer. For the latitude of $69^{\circ} \mathrm{N}$ and wavelength of $532 \mathrm{~nm}$, $\beta(\mathrm{z})$ is shown in blue in Fig. 1. We then repeat these calculations for three cases in which the initial $\mathrm{H}_{2} \mathrm{O}$ profiles are chosen $1.25,1.5$, and 2.0 times larger than our standard $\mathrm{H}_{2} \mathrm{O}$ profile. These calculations, also carried forward to day +5 , yield the black, green, and red profiles of Fig. 1, respectively. From these profiles, we obtain $\beta_{\max }=1.2,2.6,4.4$, and $8.0 \times 10^{-10} \mathrm{~m}^{-1} \mathrm{sr}^{-1}$ for $4.3,5.4,6.5$, and $8.6 \mathrm{ppm}$ water vapour, respectively. We add, that we consider $8.6 \mathrm{ppm}$ water vapour at $80 \mathrm{~km}$ and $69^{\circ} \mathrm{N}$ to be on the high side of possible $\mathrm{H}_{2} \mathrm{O}$ mixing ratios under these conditions.

For fitting our model results, we assume a dependence of NLC brightness on the ambient water vapour in the form

$\beta_{\max }=$ const $\mathrm{f}\left(\mathrm{H}_{2} \mathrm{O}\right)^{\varepsilon}$.

For a wavelength of $532 \mathrm{~nm}$ and in the range of many lidar-observed NLCs (i.e. $\beta_{\text {max }}=4$ to $10 \times 10^{-10} \mathrm{~m}^{-1} \mathrm{sr}^{-1}$ ), our COMMA/IAP results indicate a $\varepsilon \sim 2.1$. This is equivalent to saying that any $10 \%$ increase of $\mathrm{f}\left(\mathrm{H}_{2} \mathrm{O}\right)$ induces a $22 \%$ increase of $\beta_{\text {max }}$. The model result also supports Jensen and Thomas (1988) who used scaling arguments to deduce that $\beta_{\text {max }}=$ const $\mathrm{f}\left(\mathrm{H}_{2} \mathrm{O}\right)^{2}$ should hold under strong freeze drying conditions.

The CARMA model is a 2-D model that uses Eulerian transport of classes of dust and icy particles on a grid (classical volume-method). The size distribution of the condensation nuclei is calculated within the model with assumptions made about the flux of extraterrestrial matter into the upper atmosphere. In the work of Thomas et al. (2004) a onedimensional version is applied to conditions on the latitude circle $68^{\circ} \mathrm{N}$. The authors studied the sensitivity of the back scattering ratio BSR at the peak of NLC layers on the mixing ratio of ambient water vapour $\mathrm{f}\left(\mathrm{H}_{2} \mathrm{O}\right)$. For ambient conditions of $\mathrm{T}_{\text {mesopause }}=129 \mathrm{~K}$ and $\mathrm{f}\left(\mathrm{H}_{2} \mathrm{O}\right)_{80 \mathrm{~km}}=5 \mathrm{ppm}$, their model predicts also a $22 \%$ increase of BSR for any $10 \%$ increase of $\mathrm{f}\left(\mathrm{H}_{2} \mathrm{O}\right)$.

Despite some moderate differences in the modelling approaches used in these two models, we obtain close agreement in their predictions concerning changes of NLC brightness under the influence of changes in ambient water vapour. It is this model result which lends itself to a quantitative test through comparison of observed changes of NLC brightness with observed changes of water vapour. This will be done in chapter 5 .

\subsection{Solar Lyman $\alpha$ variations and ALOMAR observations} of NLC brightness

It has often been presumed that the observed quasi-periodic variation of solar Lyman $\alpha$ flux must be a dominant effect in causing decadal-scale variations in upper mesospheric water and NLC. A sensitivity study of Garcia (1989) is commonly cited for support of this assumption. Yet, even Garcia (1989)

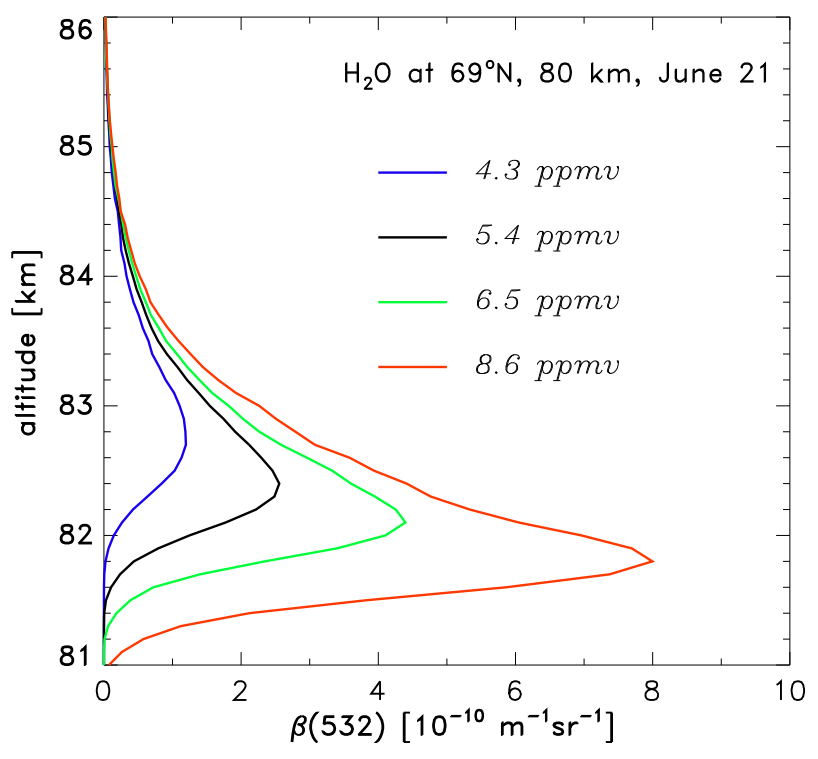

Fig. 1. Sensitivity of the zonally averaged NLC volume backscatter coefficient $\beta(532 \mathrm{~nm})$ on altitude and background water vapour abundance at $80 \mathrm{~km}$ as calculated by the COMMA/IAP model for summer solstices conditions at $69^{\circ} \mathrm{N}$ latitude.

discussed at length the fact that his 2-D model predictions did not conform to whatever relevant observations were available at the time. In addition, until today his predictions can not be verified by any relevant observations of water vapour in the NLC region.

Sonnemann and Grygalashvyly (2004) were the first to show that modern 3-D dynamic models predict a rather different reaction of the upper mesosphere water vapour to solar Lyman $\alpha$ than Garcia (1989). Sonnemann and Grygalashvyly (2004) show that the $\mathrm{H}_{2} \mathrm{O}$ mixing ratio at $80 \mathrm{~km}$ in the Arctic summer varies by only a few percent between maximum and minimum Lyman $\alpha$ flux conditions. As would be expected, the mixing ratio above $80 \mathrm{~km}$ responds more strongly to variations in solar Lyman $\alpha$, but how this is reflected in the properties of NLC was not calculated by these authors.

Here we want to quantify the potential effect of a varying flux of solar Lyman $\alpha$ on the mean NLC brightness by use of the COMMA/IAP model. To this end, we assume in a first step that solar Lyman $\alpha$ acts only to photolyze $\mathrm{H}_{2} \mathrm{O}$ (no potential thermal or plasma effects are considered). In order to model $\mathrm{H}_{2} \mathrm{O}$ photolysis, we slightly changed the chemistry part of our NLC icy particle model. Instead of our earlier simplified formula for the photolysis rate (see Eq. 4 in Berger and von Zahn, 2002) we now use the explicit data base of photolysis rates from the original chemistry module of COMMA/IAP as described by e.g. Sonnemann and Grygalashvyly (2004). In our icy particle module, the saturation pressure of water vapour is taken from Mauersberger and Krankowsky (2003). Furthermore, the water vapour photolysis rate is explicitly a function of the local zenith angle 


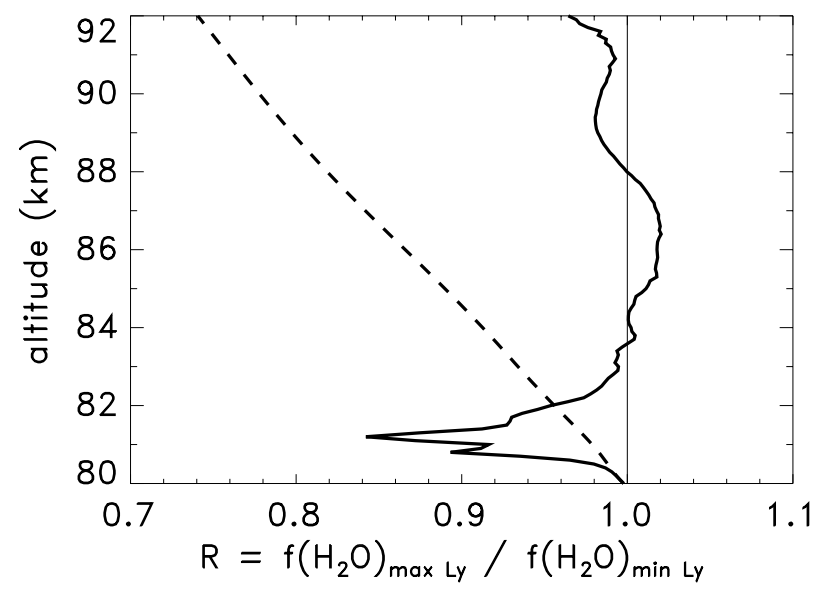

Fig. 2. The ratio $\mathrm{R}=\mathrm{f}\left(\mathrm{H}_{2} \mathrm{O}\right)_{\max \mathrm{Ly}} / \mathrm{f}\left(\mathrm{H}_{2} \mathrm{O}\right)_{\min \mathrm{Ly}}$ of the water vapour mixing ratio $\mathrm{f}$ at maximum over minimum solar Lyman $\alpha$ flux conditions as function of altitude $\mathrm{z}$, calculated by the COMMA/IAP model for summer solstices conditions at $69^{\circ} \mathrm{N}$ latitude. The dashed line indicates the modelled conditions with no formation of icy particles permitted, the solid line the modelled conditions after allowing the formation of icy particles and subsequent strong freeze-drying of the entire mesopause region.

and it allows for a variable Lyman $\alpha$ flux. The following rounded values of Lyman $\alpha$ photon flux, similar to the values of Woods et al. (2000), have been used to describe the solar activity cycle:

solar maximum conditions $\mathrm{Ly}=6.0 \times 10^{11}$ photons $\mathrm{cm}^{-2} \mathrm{~s}^{-1}$ solar minimum conditions $\mathrm{Ly}=3.5 \times 10^{11}$ photons $\mathrm{cm}^{-2} \mathrm{~s}^{-1}$

In this way we have calculated the profiles of the $\mathrm{H}_{2} \mathrm{O}$ mixing ratios $\mathrm{f}\left(\mathrm{H}_{2} \mathrm{O}\right)$ for conditions of these two Lyman $\alpha$ fluxes and the latitude of ALOMAR $\left(69^{\circ} \mathrm{N}\right)$ at the summer solstices. Figure 2 shows the modelled ratio $\mathrm{R}=\mathrm{f}\left(\mathrm{H}_{2} \mathrm{O}\right)_{\max \mathrm{Ly}} / \mathrm{f}\left(\mathrm{H}_{2} \mathrm{O}\right)_{\min \mathrm{Ly}}$. The dashed line represents the ratio $\mathrm{R}(\mathrm{t}=0)$ at time zero of our model, that is before any ice formation has started to modify this ratio. The decrease of $\mathrm{R}$ with altitude shown here is much weaker than in any previously published model. At $80 \mathrm{~km}$ altitude, the ratio R differs by only $1 \%$ from unity, whereas at $90 \mathrm{~km}$ the ratio $\mathrm{R}$ is 0.78 , indicating there a $22 \%$ smaller $\mathrm{f}\left(\mathrm{H}_{2} \mathrm{O}\right)$ at solar maximum conditions than at solar minimum. If one now allows the formation of ice and subsequent strong freezedrying, then the profiles of $\mathrm{f}\left(\mathrm{H}_{2} \mathrm{O}\right)_{\text {max }}$ Ly and of $\mathrm{f}\left(\mathrm{H}_{2} \mathrm{O}\right)_{\text {min }} \mathrm{Ly}$ develop into a nearly identical state above $83 \mathrm{~km}$. The solid line in Fig. 2 shows the ratio $\mathrm{R}$ at the model day 5.0. Now $R$ remains in the narrow range of $R=1 \pm 0.03$ over the altitude region 82.5 to $91 \mathrm{~km}$ which comprises almost the entire ice particle cloud. Hence, the process of freeze-drying does not only reduce the quantity of available gaseous water vapour in the mesopause region, it also stabilizes the amount of remnant water vapour against changes induced by outside influences. The processes remain to be identified which lead to a narrow altitude zone in which enhanced Lyman $\alpha$ fluxes induce a slight increase of water vapour mixing ratio.

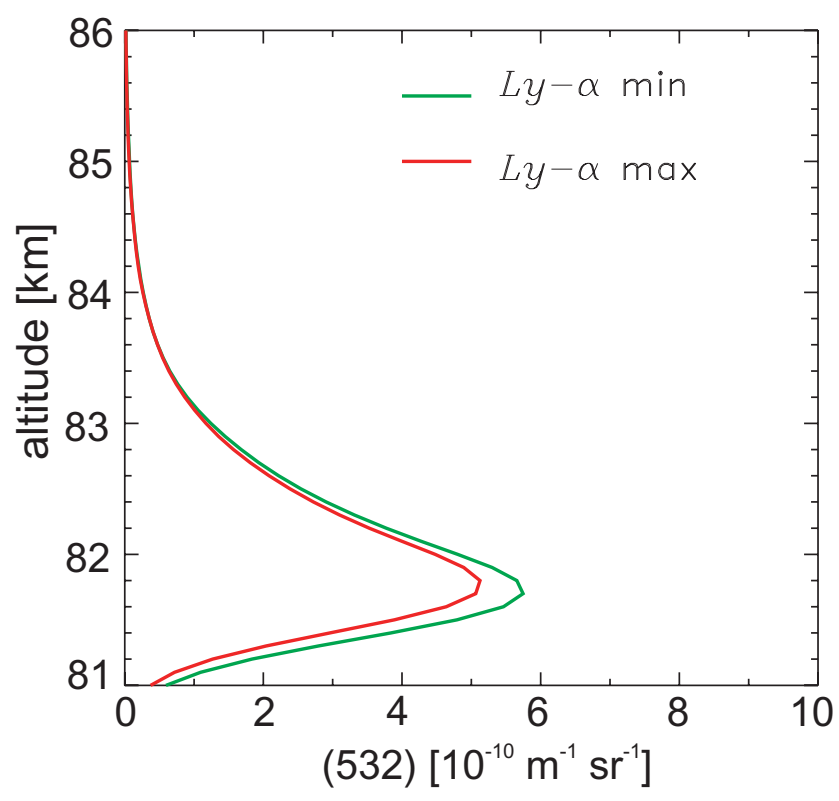

Fig. 3. The zonally averaged NLC volume backscatter coefficients $\beta\left(352 \mathrm{~nm}, 180^{\circ}\right)$ at minimum (green) and maximum (red) solar Lyman $\alpha$ flux as function of altitude $\mathrm{z}$ as calculated by the COMMA/IAP model for summer solstices conditions at $69^{\circ} \mathrm{N}$ latitude and $\mathrm{f}\left(\mathrm{H}_{2} \mathrm{O}\right)=6.0 \mathrm{ppm}$ at $80 \mathrm{~km}$.

In a second step we calculate the optical properties of the ensemble of icy particles in the ice cloud and the altitude profile of the mean volume backscatter coefficient $\beta$ for conditions appropriate for our ALOMAR lidar observations $\left(532 \mathrm{~nm}, 180^{\circ}\right)$. Figure 3 shows the resulting profiles of $\beta(532)$ for minimum and maximum solar Lyman $\alpha$ fluxes, again for the latitude of ALOMAR $\left(69^{\circ} \mathrm{N}\right)$ and summer solstices. Our model predicts only a minor increase of NLC brightness (about $+12 \%$ ) when going from our solar maximum to solar minimum conditions.

Why are our results much different from those of Garcia (1989)? A number of causes contribute to this result. In comparison to Garcia (1989), we input our model with (a) a stronger gravity wave momentum deposition leading to about twice higher vertical background winds and to reduced time scales for vertical transport of water vapour, (b) stronger vertical eddy diffusion leading to faster vertical mixing, (c) an improved $\mathrm{OH}$-photochemistry leading to enhanced chemical heating and a different partitioning of the $\mathrm{O}_{\mathrm{y}} \mathrm{H}_{\mathrm{x}}$ compounds in the mesosphere, and (d) modern data for solar Lyman $\alpha$ fluxes, comprising e.g. a smaller ratio of fluxes at solar maximum over minimum conditions. The combined effect of the changes (a) and (b) makes the time constants for vertical transport of water much smaller than those for photo dissociation of $\mathrm{H}_{2} \mathrm{O}$ by Lyman $\alpha$ anywhere below $80 \mathrm{~km}$. Thus, in our COMMA/IAP model the water vapour in the NLC region (=upper mesosphere in Arctic summer) is much less effected by variations of solar Lyman $\alpha$ fluxes than hitherto presumed. 
With this prediction being made, we see an urgent need to intensify our search for an explanation of the observed strong decadal-size NLC variations.

\subsection{Hemispheric satellite observations}

In this section we present a model simulation of hemispheric solar backscatter UV (SBUV) observations performed by satellites at a wavelength of $252 \mathrm{~nm}$ and a prediction for the dependence of the SBUV-derived NLC brightness on the background $\mathrm{H}_{2} \mathrm{O}$ mixing ratio. The simulation is performed by calculating a proxy for SBUV data making use of the hemispheric modelling of NLC with the COMMA/IAP model.

The SBUV instruments measure the solar light of $252 \mathrm{~nm}$ scattered by icy particles at latitudes southward of $82.5^{\circ} \mathrm{N}$ at scattering angles ranging from roughly $100^{\circ}$ to $140^{\circ}$ and the majority for NLC events is observed at scattering angles of $110^{\circ}$ to $130^{\circ}$. The scattering volume is defined vertically by the extent of the cloud and horizontally by the field-ofview of the detector which is roughly $150 \times 150 \mathrm{~km}$ at NLC altitude. The instrument allows to observe NLC on the ascending and descending parts of the orbit, covering typically two local solar times one in the morning and one in the afternoon. The orbit parameters give a direct correlation of local solar time of observation and scattering angle. Due to orbit changes the local solar time sampled changes throughout the years. For each year an average NLC brightness is calculated from the observations which is called the average residual albedo A (Shettle et al., 2002, 2004). This albedo A is a measure of the average over all latitudes, longitudes, and periods covered. Due to the orbit geometry this averaging performs a weighting of the latitudinal NLC coverage as the measurements are performed on a more equal latitudinal grid than on an equal area grid.

To simulate these observation conditions as well as possible with the COMMA/IAP model, we have performed the hemispheric averaging with the following assumptions:

1. The orbit inclination is $90^{\circ}$ and latitudinal weighting can be described by an equal distributed latitudinal grid.

2. The seasonal variation of cloud albedo A can be described sufficiently well by the zonal (tidal) average.

To study the impact of assumption (1) we have performed a sensitivity study including different latitude bands. For example the inclusion of particles north of $82.5^{\circ} \mathrm{N}$ has less impact on the sensitivity than the changing scattering angle. Assumption (2) is the major caveat but the computational power available to us does not allow to perform the necessary model simulations covering the complete NLC season up to now. Figure 4 shows the particle size distributions for the entire hemispheric ice cloud and for different water vapour concentrations calculated from the 3-D COMMA/IAP model including the latitudinal weighting. These distributions are extraordinarily wide and show neither a clear growth mode nor

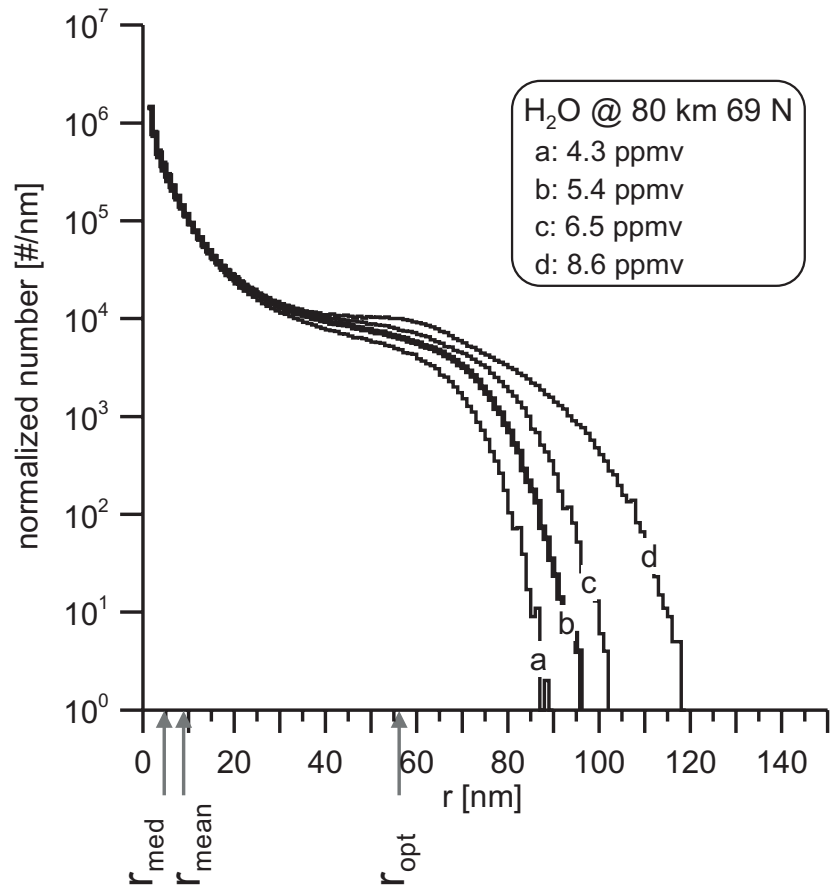

Fig. 4. Particle size distributions calculated by the COMMA/IAP model for the entire summer upper mesosphere ice cloud and used in simulations of the hemispheric SBUV radiance observations at $252 \mathrm{~nm}$ and for different water vapour mixing ratios $\mathrm{f}\left(\mathrm{H}_{2} \mathrm{O}\right)$ at $80 \mathrm{~km}$ and $69^{\circ} \mathrm{N}$. The median, mean, and optical radii are indicated for the distribution with $\mathrm{f}\left(\mathrm{H}_{2} \mathrm{O}\right)=5.4 \mathrm{ppm}$ at $80 \mathrm{~km}$.

an evaporation mode. This character of the distributions is caused by the extensive averaging over all altitudes and all latitudes at which the polar summer ice cloud exists. The distributions are strongly dominated by the small, invisible icy particles which make up the upper part of the ice cloud It is obvious that these distributions are quite different from a local NLC particle size distribution close to the peak of an NLC layer for which a single growth mode is presumed and described by a log-normal distribution (see e.g. von Cossart et al., 1999). Yet, we argue that our hemispheric distributions need to represent the entire, persistent ice cloud about the polar summer mesopause and do so much better than any log-normal distribution.

We want the reader to be aware of the fact that such wide distributions can not easily be characterized by a single "radius" for its particles. As an example, we have included in Fig. 4 radii as typically used to describe particle distributions on purely statistically and optically weighted statistically means for the case of $\mathrm{f}\left(\mathrm{H}_{2} \mathrm{O}\right)=5.4 \mathrm{ppmv}$. For the optical signal observed by the SBUV instrument at $252 \mathrm{~nm}$, the largest contribution comes from particles with a radius of $56 \mathrm{~nm}$ which we call the optical radius $\mathrm{r}_{\text {opt }} .75 \%$ of the total optical signal comes from particles with radii larger than $45 \mathrm{~nm}$. Furthermore, the optical radius depends only slightly $( \pm 4 \mathrm{~nm})$ on the scattering angle $\alpha$. For the same 
Table 1. Sensitivity of the $252 \mathrm{~nm}$ albedo A against changes in $\mathrm{f}\left(\mathrm{H}_{2} \mathrm{O}\right)$.

\begin{tabular}{cccc}
\hline $\begin{array}{c}\text { Absolute change of } \\
\mathrm{f}\left(\mathrm{H}_{2} \mathrm{O}\right) \text { [ppm] }\end{array}$ & $\begin{array}{c}\text { Relative change of } \\
\mathrm{f}\left(\mathrm{H}_{2} \mathrm{O}\right)=\mathrm{d} \mathrm{H}_{2} \mathrm{O}\end{array}$ & $\begin{array}{c}\text { modelled albedo } \\
\text { change dA }\end{array}$ & $\begin{array}{c}\mathrm{dA} \text { for } \\
\mathrm{d} \mathrm{H} \mathrm{H}_{2} \mathrm{O}=10 \%\end{array}$ \\
\hline from 4.30 to 5.38 & $22.2 \%$ & $31.4 \%$ & $14 \%$ \\
from 5.38 to 6.45 & $18.2 \%$ & $21.3 \%$ & $12 \%$ \\
from 6.45 to 8.60 & $28.6 \%$ & $34.1 \%$ & $12 \%$ \\
\hline
\end{tabular}

Table 2. Longer term observations of upper mesosphere $\mathrm{H}_{2} \mathrm{O}$ (in approximate historical order).

\begin{tabular}{|c|c|c|c|c|c|}
\hline $\begin{array}{c}\text { Northern } \\
\text { hemisphere } \\
\text { observations }\end{array}$ & Instrument & $\begin{array}{l}\text { Latitude(s) } \\
\text { of observation }\end{array}$ & $\begin{array}{l}\text { Altitude of } \\
\text { episodic } \\
\text { change }\end{array}$ & $\begin{array}{l}\text { Episodic change } \\
\text { [ppmv/year] }\end{array}$ & References \\
\hline 1992-1996 & $\begin{array}{c}\text { HALOE @ UARS } \\
\text { (solar occultation } \\
\text { limb sounding) }\end{array}$ & $\begin{array}{l}34^{\circ} \mathrm{N} \\
\pm 5^{\circ}\end{array}$ & $70 \mathrm{~km}$ & +0.20 & Nedoluha et al. (1998) \\
\hline 1993-1996 & $\begin{array}{c}\text { Table Mountain } \\
\text { ground-based microwave } \\
\text { spectrometer }\end{array}$ & $34^{\circ} \mathrm{N}$ & $70 \mathrm{~km}$ & +0.19 & Nedoluha et al. (1998) \\
\hline 1995-2001 & $\begin{array}{l}\text { ALOMAR } \\
\text { ground-based }\end{array}$ & $67^{\circ} \mathrm{N}$ & $77.5 \mathrm{~km}$ & $-0.045 \pm 0.006$ & $\begin{array}{c}\text { Seele and Hartogh (1999) } \\
\text { Hartogh et al. (2001) }\end{array}$ \\
\hline $\begin{array}{l}\text { summers } \\
1996-2000\end{array}$ & $\begin{array}{l}\text { microwave } \\
\text { spectrometer } \\
\text { WASPAM }\end{array}$ & $67^{\circ} \mathrm{N}$ & 80 km & $+\mathbf{0 . 0 5} \pm \mathbf{0 . 0 1}$ & this work \\
\hline $1997-2002$ & $\begin{array}{l}\text { Hawaii ground-based } \\
\text { microwave spectrometer }\end{array}$ & $20^{\circ} \mathrm{N}$ & $70 \mathrm{~km}$ & -0.108 & Nedoluha et al. (2003) \\
\hline 1997-2002 & $\begin{array}{l}\text { HALOE @ UARS } \\
\text { (solar occultation } \\
\text { limb sounding) }\end{array}$ & $\begin{array}{l}20^{\circ} \mathrm{N} \\
\pm 5^{\circ}\end{array}$ & $70 \mathrm{~km}$ & -0.163 & Nedoluha et al. (2003) \\
\hline
\end{tabular}

distributions, the mean and median particle radii are, however, only 8 and $5 \mathrm{~nm}$, respectively. Hence, the median radius is an order of magnitude smaller than the optical radius $r_{o p t}$.

The optical signal produced by the entire ice cloud and received at satellite altitudes by a SBUV instrument was calculated from the particle distribution sampled in $1 \mathrm{~nm}$ bins using the scattering of spherical particles at $120^{\circ}$ phase angle. Similar to the procedure described in Sect. 2.1, we initialize the COMMA/IAP model calculation of the NLC scattered radiance with our standard $\mathrm{H}_{2} \mathrm{O}$ profile for 21 June having $\mathrm{f}\left(\mathrm{H}_{2} \mathrm{O}\right)=4.3 \mathrm{ppm}$ at $80 \mathrm{~km}$ and run the model to day +5 . We then repeat these calculations for three more cases in which the initial $\mathrm{H}_{2} \mathrm{O}$ profiles are chosen $1.25,1.5$, and 2.0 times larger than our standard $\mathrm{H}_{2} \mathrm{O}$ profile. From these four model runs, we obtain the mean hemispheric albedo changes dA for three steps in $\mathrm{f}\left(\mathrm{H}_{2} \mathrm{O}\right)$ as listed in Table 1. For a value of $\mathrm{f}\left(\mathrm{H}_{2} \mathrm{O}\right)=6 \mathrm{ppm}$ at $80 \mathrm{~km}$, the signal change $\mathrm{dA}$ is $12 \%$ per $10 \% \mathrm{df}\left(\mathrm{H}_{2} \mathrm{O}\right)$ change with an uncertainty of $1 \%$ given by the range of absolute scattering angles $\alpha$ encountered by SBUV.
If compared to our $532 \mathrm{~nm}$ backscatter calculations for $67.5^{\circ} \mathrm{N}$ of Sect. 2.1, the calculations of $252 \mathrm{~nm}$ hemispheric average residual albedo $\mathrm{A}$ show a smaller dependence on the background mixing ratio $\mathrm{f}\left(\mathrm{H}_{2} \mathrm{O}\right)$. This smaller dependence on the $\mathrm{H}_{2} \mathrm{O}$ abundance is caused (a) mostly by the shorter wavelength of $252 \mathrm{~nm}$ and (b) by the wider particle size distribution encountered in the hemispheric sampling of the SBUV instruments as compared to our local $532 \mathrm{~nm} \mathrm{li-}$ dar measurements. As regards (a), at a fixed wavelength the scatter cross section of a single particle as function of the particle radius passes through a marked minimum when going from the Rayleigh scatter into the Mie scatter regime. At $252 \mathrm{~nm}$ this minimum in scatter cross section occurs at a single particle radius $r$ close to $80 \mathrm{~nm}$. For a particle ensemble with a lognormal radius distribution and distribution width $\sigma=1.4$, the minimum slope of $\mathrm{d} \beta / \mathrm{dr}$ occurs, however, close to a particle radius of $50 \mathrm{~nm}$ which is also close to the optical radius $\mathrm{r}_{\text {opt }}$ of the mean hemispheric particle distribution. For a hemispheric-mean particle size distribution, its width $\sigma$ is so large, however, that the "single particle minimum" is very 
much smeared out and a genuine minimum of scatter coefficient $\beta$ versus median radius $\mathrm{r}_{\text {med }}$ does not exist anymore. What remains of the minimum is only a moderate change in the positive gradient of the scatter coefficient $\beta$ with increasing $\mathrm{r}_{\text {med }}$.

We summarize the basic results of the COMMA/IAP model concerning the sensitivity of NLC brightness on the background water vapour at $80 \mathrm{~km}$ altitude as follows: For lidar backscatter observations at $532 \mathrm{~nm}$ our model predicts a $22 \%$ increase of $\beta$ for a $10 \%$ increase of $\mathrm{f}\left(\mathrm{H}_{2} \mathrm{O}\right)$, whereas for hemispheric SBUV observations at $252 \mathrm{~nm}$ it predicts only a $12 \%$ increase of the albedo A for the same increase in $\mathrm{f}\left(\mathrm{H}_{2} \mathrm{O}\right)$.

\section{Measurements of mesospheric water vapour}

For studies of episodic changes of NLC parameters it would be best if they could be based on decades-long and accurate observations of the mixing ratio $\mathrm{f}\left(\mathrm{H}_{2} \mathrm{O}\right)$ in the NLC region. The latter we wish to define as the region between 80 and $85 \mathrm{~km}$ at polar latitudes (poleward of $67^{\circ}$ ) in mid-summer. Yet, no such measurements have been published so far. Consequently, we base this study on two types of $\mathrm{H}_{2} \mathrm{O}$ observations which miss out on only one of the above conditions: (1) Observations of the $\mathrm{H}_{2} \mathrm{O}$ mixing ratio $\mathrm{f}$ in the NLC region, yet of only 5 years duration and (2) a decade long series of $\mathrm{H}_{2} \mathrm{O}$ observations, yet only at mid and low latitudes.

For the aims of our own study, the most useful information comes from the observations by the ground-based ALOMAR microwave spectrometer for water and trace gas measurements in the middle atmosphere (WASPAM) of Hartogh et al. (2001). Being located in the Arctic at $69.3^{\circ} \mathrm{N}$, the instrument looks at $18^{\circ}$ elevation towards the South (Hartogh and Jarchow, 1995). It thus samples the upper mesosphere close to $67^{\circ} \mathrm{N}$ (see Table 2). It went into operations in 1995 and complete summer data are available for the years 1996 through 2000 (due to an instrument refurbishment, $\mathrm{H}_{2} \mathrm{O}$ data were obtained for only parts of the summers 2001 and 2002; The data of 2003 and 2004 are still being processed and are not yet available for this publication).

Further information comes from satellite-borne solar occultation limb soundings at $6.6 \mu \mathrm{m}$ (HALOE instrument onboard the UARS satellite) and ground-based microwave spectrometry at $22 \mathrm{GHz}$ (two more instruments at mid and low latitudes) which we present also in Table 2. For the northern hemisphere, the data records of these instruments started in 1992. Their strength is the longer observation period as compared with that of the Arctic ALOMAR microwave spectrometer. Their shortcoming is the latitude coverage: The HALOE observations reach only barely into the Arctic and results on episodic changes of water vapour in the Arctic have not been published so far; The other microwave spectrometers do not monitor Arctic conditions at all.

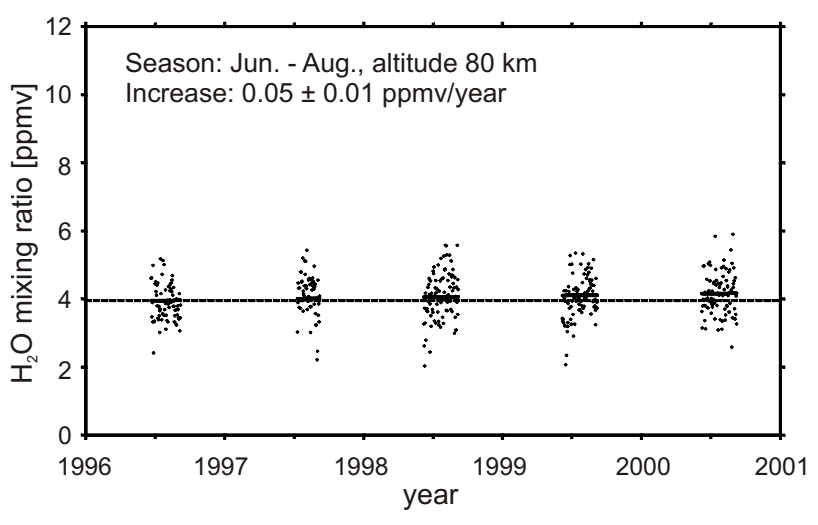

Fig. 5. The $\mathrm{H}_{2} \mathrm{O}$ mixing ratio as measured by the ALOMAR microwave spectrometer at $80 \mathrm{~km}$ altitude during the months June, July, and August of the years 1996 through 2000. The dashed line marks the mean $\mathrm{H}_{2} \mathrm{O}$ mixing ratio as observed in the summer 1996 , the short black lines indicate a linear regression for all data points shown. Each data point is a $24-\mathrm{h}$ mean.

As regards the Arctic microwave data, Hartogh et al. (2001) have previously published their analysis of interannual variations of the mesospheric water vapour at ALOMAR. They retrieved water vapour mixing ratios $\mathrm{f}\left(\mathrm{H}_{2} \mathrm{O}\right)$ for the time period late 1995 until mid-2001. Their highest altitude band was centered at $77.5 \mathrm{~km}$, for which altitude Hartogh et al. (2001) found a significant decrease of upper mesosphere water vapour by $-0.045 \pm 0.006 \mathrm{ppmv} /$ year (Table 2 ). We emphasize, though, that this result was derived from a fit to all observations, regardless of their sampling season. Here we allow in addition for the possibility that the episodic changes of $\mathrm{f}\left(\mathrm{H}_{2} \mathrm{O}\right)$ might be different in summer and winter. To test this hypothesis, we have studied the $80 \mathrm{~km}$ data of the ALOMAR microwave spectrometer for the periods of only June through August of the years 1996 through 2000. These are shown in Fig. 5, in which each data point is a 24-h mean. The dashed line marks the mean $\mathrm{H}_{2} \mathrm{O}$ mixing ratio as observed in the summer 1996, the short black lines indicate a linear regression for all data points shown. We choose the analysis altitude to be $80 \mathrm{~km}$, in this way coming closer to the NLC region than before. We performed a linear regression of these data which yields a change of water vapour mixing ratio $\mathrm{f}\left(\mathrm{H}_{2} \mathrm{O}\right)$ by $+0.05 \pm 0.01 \mathrm{ppmv} / \mathrm{year}$ (Table 2 ). The error bar includes only the statistical fluctuations of all the data points. Most notably, for the summer periods this episodic change is positive and thus differs not only in magnitude, but also in sign from the changes derived for the same location, but from annual means.

The HALOE observations of upper mesosphere water vapour have been treated by a number of authors. As regards studies of long term changes, the most recent studies are those of Randel et al. (2000) and Marsh et al. (2003), but both are based on complete annual means, not seasonally 
separated data samples. In Fig. 5 of Randel et al. (2000), $\mathrm{H}_{2} \mathrm{O}$ trends are shown for latitudes $\leq 55^{\circ}$ and altitudes $\leq 78 \mathrm{~km}$. For the time period 1995-1999, the episodic changes of $\mathrm{f}\left(\mathrm{H}_{2} \mathrm{O}\right)$ are negative above $70 \mathrm{~km}$ and at all latitudes shown. The results are, however, statistically significant in only a portion of this region. In the paper of Marsh et al. (2003), the most northerly region studied is the latitude band $35^{\circ} \mathrm{N} \pm 17.5^{\circ}$. For this latitude band, Marsh et al. (2003) show in their Fig. 3 monthly means of water vapour at $0.011 \mathrm{hPa}(\sim 80 \mathrm{~km})$ which again exhibit a decrease of $\mathrm{f}\left(\mathrm{H}_{2} \mathrm{O}\right)$ since the mid-1990s. We need to emphasize, though, that neither study addresses the question of trends at high or polar latitudes.

HALOE observations at high latitudes have been analysed by McHugh et al. (2003) and Hervig et al. (2003). Both teams expanded their studies to latitudes of up to $70^{\circ} \mathrm{N}$ and altitudes of up to $88 \mathrm{~km}$. Yet all their results are based on averages over the period 1992-2002 and no information on interannual or episodic variations is given in these papers.

At low latitudes, mesospheric water vapour has been obtained also from ground-based microwave spectrometers located at $20^{\circ} \mathrm{N}$ and $34^{\circ} \mathrm{N}$ (Table 2). Nedoluha et al. (2003) analysed water vapour measurements performed at and close to $20^{\circ} \mathrm{N}$ from 1997 to 2002 by both their ground-based microwave spectrometer and the HALOE instrument. Their trend analysis is again based on their entire data sets (not seasonally separated). Nedoluha et al. (2003) obtain for $70 \mathrm{~km}$ altitude changes of $\mathrm{f}\left(\mathrm{H}_{2} \mathrm{O}\right)$ by $-0.108 \mathrm{ppmv} /$ year and $-0.163 \mathrm{ppmv} / \mathrm{year}$ from the microwave spectrometer and HALOE observations, respectively. Hence, from 1997 to 2002 the upper mesosphere at $20^{\circ} \mathrm{N}$ lost, say, $(0.136 \mathrm{ppmv} \times 5) \sim 0.7 \mathrm{ppmv}$ or $12 \%$ of its total water content. This scenario of significantly decreasing water mixing ratios is clearly much different in character from that which we deduce for the Arctic ALOMAR site in summer. We remind the reader, though, that the decreases of water vapour at low and mid latitudes are derived from the linear term of a multi-parameter least squares fit to the entire data set, whereas the increases of water vapour at an Arctic latitudes comes from only summer months data. The data points for $\mathrm{f}\left(\mathrm{H}_{2} \mathrm{O}\right)$ as presented in Fig. 3 of Nedoluha et al. (2003) make it amply clear that also at $20^{\circ} \mathrm{N}$ latitude, a large annual variation of the water mixing ratio at $70 \mathrm{~km}$ altitude is indicated in both the HALOE and microwave data. But different from the Arctic latitudes, at $20^{\circ} \mathrm{N}$ even the summer values of $\mathrm{f}\left(\mathrm{H}_{2} \mathrm{O}\right)$ show a significant negative trend.

Do the observed changes of upper mesosphere water vapour since 1996 represent a "long term trend"? Certainly not. This is because during the period 1992 to 1996 and at $34^{\circ} \mathrm{N}$, water at $70 \mathrm{~km}$ altitude increased rapidly at a rate of 0.2 ppmv/year as indicated in Table 2 and discussed in detail by Nedoluha et al. (1998). This dramatic increase of upper mesospheric water vapour by about $1 \mathrm{ppmv}(\sim 20 \%)$ over 5 years was seen by both ground-based and satellite-borne instruments. Hence, the decade between 1992 and 2002 is characterized by first a strong increase and then a somewhat more moderate decrease of the $\mathrm{H}_{2} \mathrm{O}$ mixing ratio in the upper mesosphere at low and mid latitudes. These episodic variations can hardly be described by a constant trend.

Recalling Table 2, we summarize these results as follows: At low and mid latitudes, the upper mesospheric water vapour has dramatically increased from 1992 to 1996 and decreases slowly since. So far, there are little more than speculations about the reasons for the almost globally observed dramatic change of the trend of the mesospheric $\mathrm{H}_{2} \mathrm{O}$ which occurred in the mid-1990s. Even at the one station available in the Arctic, the upper mesospheric water vapour has gone down since 1995, provided we base this analysis on annual means. If we study in the Arctic, however, only the three summer months of June through August, then the upper mesospheric water vapour is found to be on a slow rise since this observation series started in summer of 1996.

\section{Measurements of NLC brightness}

\subsection{ALOMAR ground-based lidar measurements}

Ground-based lidar observations of NLC allow accurate measurements of the NLC backscatter coefficients $\beta$ and their altitude dependence, provided the instrument can perform these measurements in full daylight. The ALOMAR Rayleigh/Mie/Raman lidar (RMR lidar) was designed and built with this aim in mind (von Zahn et al., 2000) and has achieved this goal since the summer of 1997. Starting with this summer the instrument crew maintained an essentially 24-h operational readiness of the instrument from 1 June through 15 August in each summer season. On average, the lidar provided high quality data on overhead NLC for about $100 \mathrm{~h}$ per season (Fiedler et al., 2003). Here we deal exclusively with the data obtained by the instrument at $532 \mathrm{~nm}$ wavelength.

From the lidar-observed photon count rates, we derive the NLC volume backscatter coefficients in a manner as described in detail by Fiedler et al. (2003). The integration time for a single NLC profile is typically $14 \mathrm{~min}$ which yields more than 400 NLC profiles and their $\beta$-value at the NLC layer peaks per annum. From these data, we calculate two different kinds of annually averaged NLC brightness values: (a) A mean backscatter coefficient $\beta$ from all observed NLC profiles and (b) a normalized backscatter coefficient $\beta_{n}=\beta \times \mathrm{OP}$, where $\mathrm{OP}$ is the mean occurrence probability of NLC being detected overhead ALOMAR during all times of lidar observations of a particular year. The parameter $\beta_{n}$ encompasses the fact that at $69^{\circ} \mathrm{N}$ there are many days during any NLC season (here defined to last from 1 June through 15 August) which do not exhibit any detectable NLC. Hence, we expect $\beta_{n}$ to reflect better than $\beta$ the mean brightness of NLC layers during a particular NLC season. 
Table 3. Summer means of NLC backscatter coefficients $\beta$ and $\beta_{n}$ at the layer peaks and NLC occurrence probabilities OP as measured by the ALOMAR RMR lidar in units of $\left[10^{-10} \mathrm{~m}^{-1} \mathrm{sr}^{-1}\right]$.

\begin{tabular}{ccccc}
\hline Year & Mean $\beta$ & OP & $\beta_{n}=\beta \times \mathrm{OP}$ & $\delta \beta_{n}$ \\
\hline 1997 & 14.22 & 0.41 & 6.16 & 0.61 \\
1998 & 10.02 & 0.34 & 3.56 & 0.29 \\
1999 & 9.96 & 0.23 & 2.55 & 0.29 \\
2000 & 6.74 & 0.5 & 3.71 & 0.28 \\
2001 & 8.96 & 0.26 & 2.51 & 0.28 \\
\hline Means & 10 & 0.35 & 3.7 & \\
\hline
\end{tabular}

With Table 3 we introduce the summer means of a number of lidar-observed NLC properties for the years that we have ALOMAR lidar observations overlapping with those of the ALOMAR $\mathrm{H}_{2} \mathrm{O}$ microwave spectrometer, that are the years 1997 through 2001. The occurrence probabilities differ slightly from the values given by Fiedler et al. (2003). This is because we use here a different method for their calculation in order to produce also error bars for the mean normalized backscatter coefficient $\beta_{n}$. These $\beta_{n}$ do not show any significant increase or decrease during the four years 1998 through 2001. However, $\beta_{n}(1997)$ is clearly higher than the other four $\beta_{n}$ values. Its error bar $\delta \beta_{n}(1997)$ is considerably larger than those for the following years, mostly due to poorer observations statistics and uneven seasonal coverage. We will discuss these results in more detail in Sect. 5.1.

Last, but not least, we note that the mean of the observed normalized backscatter coefficients $\beta_{n}=3.7 \times 10^{-10} \mathrm{~m}^{-1} \mathrm{sr}^{-1}$, can be compared with the results of the COMMA/IAP model of Fig. 1 which represent climatological mean values of $\beta(\mathrm{z})$ with an occurrence probability OP $\sim 1$. This comparison yields a "best fitting" $\mathrm{H}_{2} \mathrm{O}$ mixing ratio at $80 \mathrm{~km}$ of slightly above $6 \mathrm{ppm}$ which is a factor 1.5 higher than the observed summer mean of the ALOMAR $\mathrm{H}_{2} \mathrm{O}$ microwave spectrometer. Which part of this factor 1.5 is caused by the statistical error bars of the measurements, by uncertainties in the inversion of the microwave raw data, uneven seasonal coverage of the observations, averaging over nonlinear effects, or shortcomings in the model calculations remains to be investigated.

\subsection{Hemispheric satellite SBUV observations}

The second type of observation that we are to discuss is that of NLC measurements as performed by satellite-borne, nadir-pointing Solar Backscattered Ultraviolet (SBUV) instruments. These instruments detect NLC in the wavelength band 252 to $292 \mathrm{~nm}$. Since 1978 there have been six different SBUV instruments which have provided NLC observations with at least one, but usually more than one season of overlap between successive instruments. Results of the northern

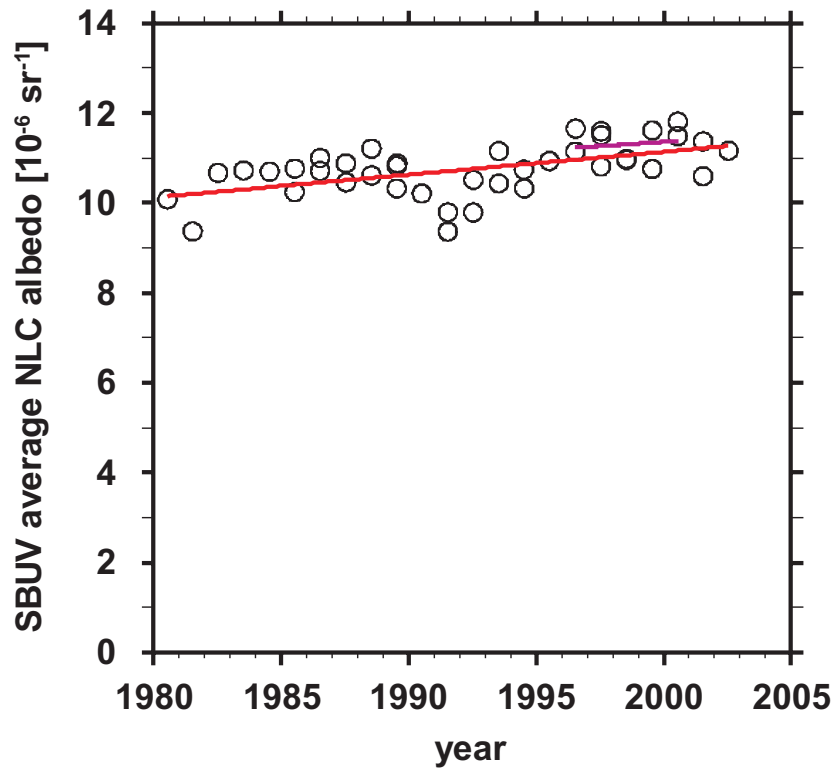

Fig. 6. Average residual NLC albedo A as derived from SBUV observations from 1981-2002 and linear regression lines for the data from 1981-2002 (red line) and from 1996-2000 (magenta line). Data points are taken from Fig. 6a of Thomas et al. (2004).

hemisphere observations are now available for 24 summer seasons. Details of this unique long term record of NLC parameters were recently reported by DeLand et al. (2003) who focus their analysis on the occurrence rate and by Shettle et al. (2002, 2004) and Thomas et al. (2004) who focus on the albedo A of NLCs.

Shettle et al. (2004) calculate the annually averaged NLC albedo A for each NLC season 1979 through 2002 and each satellite as numerical average of the residual albedo of all clouds that exceed the albedo detection threshold of $7 \times 10^{-6}$. They fit the albedo values A by an expression which is linear in time and the solar Lyman $\alpha$ flux plus a constant. The term of the fit, which is linear in time (="secular" term), yields for the Northern hemisphere an NLC albedo increase of $+0.3 \%$ /year.

Thomas et al. (2004) also performed an analysis of the same SBUV data as used by Shettle et al. (2004), but using an analysis method different from that of Shettle et al. (2004). Hence, the albedo values A in Fig. 6a of Thomas et al. (2004) turn out slightly different from those in Fig. 1 of Shettle et al. (2004). Here we show in Fig. 6 the SBUV albedo values A as taken from Fig. 6a of Thomas et al. (2004). We add the zero line and our own regression lines (in red and magenta) to the data points. The long-term regression line (in red) turns out very similar to the secular term of Thomas et al. (2004). Our regression line indicates a secular increase of the NLC albedo by $+0.51 \% / y e a r$ (whereas Thomas et al. (2004) quote $+0.4 \%$ ). Over the 24-year observation period, this amounts to a total increase of A by $12 \%$. 


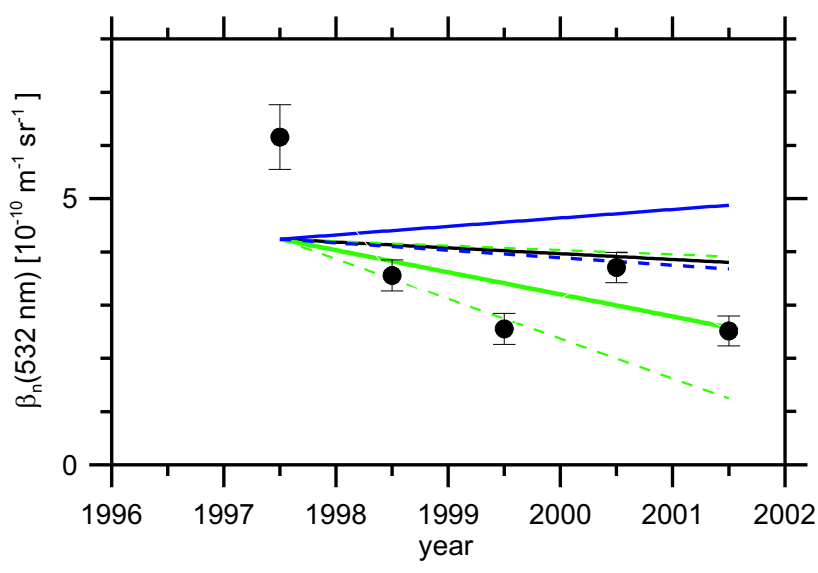

Fig. 7. Normalized summer means of NLC backscatter coefficients $\beta_{n}(532)$ at the layer peaks (black circles) as measured by the ALOMAR RMR lidar since 1997. The solid green line is a linear fit to these lidar data, taking into account the error bars of the $\beta_{n}$ values. The dashed green lines give the minimum and maximum slopes of the fit line allowed by a $68 \%$ significance limit. The solid blue, dashed blue, and black lines delineate the slope of $\beta_{n}$ as predicted by the COMMA/IAP model assuming that all the $\beta_{n}$ change is caused by the change of ambient water vapour as observed in summer and over the entire year by the ALOMAR microwave spectrometer, or by the coincident increase of solar Lyman $\alpha$ flux, respectively.

\section{Comparison of observed and modelled changes of NLC brightness}

In the previous two chapters we have reviewed the magnitude of observed episodic changes in NLC brightness and albedo as well as those of the ambient water vapour and solar Lyman $\alpha$ fluxes. In this chapter, we will study to what extent our model calculations are able to identify the causes for the observed episodic changes in NLC brightness and albedo.

\subsection{ALOMAR ground-based measurements}

It has become obvious in Sect. 3 that the episodic changes of upper mesosphere water mixing ratio $\mathrm{f}\left(\mathrm{H}_{2} \mathrm{O}\right)$ depend strongly on both latitude and season. A factual comparison of observed episodic changes of NLC parameters with those predicted by models can therefore be done only with water vapour data collected in summer at polar latitudes. Fortunately, there is at least one set of observations available which meets these criteria: the ground-based microwave observations of upper mesosphere $\mathrm{H}_{2} \mathrm{O}$ at the ALOMAR observatory. Even though this record started only in summer 1996, we want to compare the available observations with model predictions as closely as possible. In a second step, we will discuss our COMMA/IAP model result on the influence of Lyman $\alpha$ variations on upper mesosphere $\mathrm{H}_{2} \mathrm{O}$ and NLC brightness. In these studies, we have to accept the fact that the ground-based lidar and microwave $\mathrm{H}_{2} \mathrm{O}$ observations overlap for "only" a period of 5 summers. We consider this length of time well suited to look for episodic changes, but certainly not for any long-term trends.

In Fig. 7 the black circles indicate the normalized summer means of NLC backscatter coefficients $\beta_{n}$ at the layer peaks and their error bars as determined from observations by the ALOMAR RMR lidar since 1997. The solid green line is a linear fit to these lidar data, taking into account the error bars of the $\beta_{n}$ values. The dashed green lines give the minimum and maximum slopes of the fit line allowed by a $68 \%$ significance limit.

The solid and dashed blue lines of Fig. 7 mark the changes of $\beta_{n}$ as predicted by Eq. (1) and the COMMA/IAP model and assuming that all the change is caused by changes of ambient water vapour as observed by the ALOMAR microwave spectrometer in summer and year-round, respectively.

The black line of Fig. 7 marks the change of $\beta_{n}$ as predicted by the COMMA/IAP model assuming that all the change is caused by a coincident increase of solar Lyman $\alpha$ flux (from 3.6 to $5.3 \times 10^{11}$ photons $\mathrm{cm}^{-2} \mathrm{~s}^{-1}$ between the summers of 1997 and 2001) and its photo dissociation of upper mesosphere water vapour (see Sect. 2.2).

We recognize that over the 5-year period of these measurements the observed decrease of NLC brightness $\beta_{n}$ can not be satisfactorily explained by the increase of solar Lyman $\alpha$ flux nor is it in accordance with the observed summer increase of water vapour. There are a number of scenarios which might be responsible for this situation: (1) The observed changes of NLC brightness are due to other causes than considered so far. Candidate causes are small changes in the thermal structure of the mesopause region and/or changed dynamics; (2) The wave-driven variability of NLC brightness is simply too large to allow any robust conclusions from a short observation period as ours; (3) We are still missing an important process in our modelling of the polar summer mesopause region. We compare this situation with that of the water vapour in the middle mesosphere which we have shown here to have exhibited dramatic changes in the past decade which are also not understood and which are still beyond any robust model calculations.

\subsection{Hemispheric satellite SBUV observations}

As we have shown in chapter 3, episodic changes of the water vapour mixing ratio $\mathrm{f}\left(\mathrm{H}_{2} \mathrm{O}\right)$ in the upper mesosphere can be quite different for different seasons of the year and different latitudes. In our search for potential cause(s) of decadal-scale variations in the residual NLC albedo A, we best compare observed variations of $A$ with measurements of $f\left(\mathrm{H}_{2} \mathrm{O}\right)$ performed in the Arctic summer. However, such $\mathrm{f}\left(\mathrm{H}_{2} \mathrm{O}\right)$ measurements are currently available only for the summer periods of 1996 through 2000. Hence, we perform a linear fit to the SBUV-observed albedo data of Fig. 6 for just this period. The regression line is shown (in magenta) and yields an absolute $\mathrm{A}$ increase of $(+0.037 \pm 0.195) \times 10^{-6} /$ year which equals 
$+0.33 \% / y e a r$. We certainly recognize that the statistical significance of this episodic change in NLC brightness is low. We note, though, the fact that its sign is positive just like the one derived from the summer ALOMAR water vapour observations. In addition, both parameters $\mathrm{A}$ and $\mathrm{f}\left(\mathrm{H}_{2} \mathrm{O}\right)$, which are monitored in the Arctic summer, show episodic changes quite different from those which the upper mesosphere water vapour undergoes at mid and low latitudes (see Neduloha et al., 2003).

How would the various observed episodic changes of the mesospheric $\mathrm{f}\left(\mathrm{H}_{2} \mathrm{O}\right)$ impact the record of observed NLC albedo values $\mathrm{A}$ ? To give at least a semi-quantitative answer to this question, we have developed Fig. 8 which shows the observed A values (black circles) as published in Thomas et al. (2004) and a linear fit through their data points from 1996 through 2000 (magenta line). Additional coloured lines indicate how the albedo A should have developed according to the COMMA/IAP model under the influence of observed changes in water vapour (according to Table 1) and solar Lyman $\alpha$ since 1996 . We choose as a reference point the A value as indicated by the magenta fit line in summer 1996 , which is $11.2 \times 10^{-6}$. For this sensitivity study, we take the observed episodic changes of $\mathrm{f}\left(\mathrm{H}_{2} \mathrm{O}\right)$ as listed in Table 2 from summer 1996 until summer 2000. The tabulated values of $\mathrm{f}\left(\mathrm{H}_{2} \mathrm{O}\right)$ /year are first converted to percentage changes per year, then multiplied with the model-derived factor 1.12 to convert them into percentage changes of $\mathrm{A} / \mathrm{year}$, then multiplied by 4 years and finally converted to absolute A changes over 4 years using the mean A value of $11.2 \times 10^{-6}$ (see above). This yields the solid blue line for the ALOMAR microwave spectrometer observations in summer, the dashed blue line for the annually averaged ALOMAR microwave spectrometer observations, the short dashed red line for the annually averaged microwave spectrometer observations at $20^{\circ} \mathrm{N}$, and the long dashed red line for the annually averaged HALOE observations at $20^{\circ} \mathrm{N}$ (the latter two lines are drawn until 2002 because their observations are available for the entire time period). In addition, a black line indicates the modelled decrease of NLC albedo under the influence of the observed increase in solar Lyman $\alpha$ flux (and presumed constant $\mathrm{f}\left(\mathrm{H}_{2} \mathrm{O}\right)$ ).

One recognizes that fit of the SBUV-observed NLC albedo is best matched by the blue solid line, which was derived from July-through-August means of $\mathrm{f}\left(\mathrm{H}_{2} \mathrm{O}\right)$ observed in the Arctic between 1996 and 2000. The large decreases of $\mathrm{f}\left(\mathrm{H}_{2} \mathrm{O}\right)$ as derived from annually averaged observations at Arctic and low latitudes (dashed blue and red lines, respectively) seem to be ruled out for the NLC region because they are in conflict with the near constancy of observed NLC albedo A.

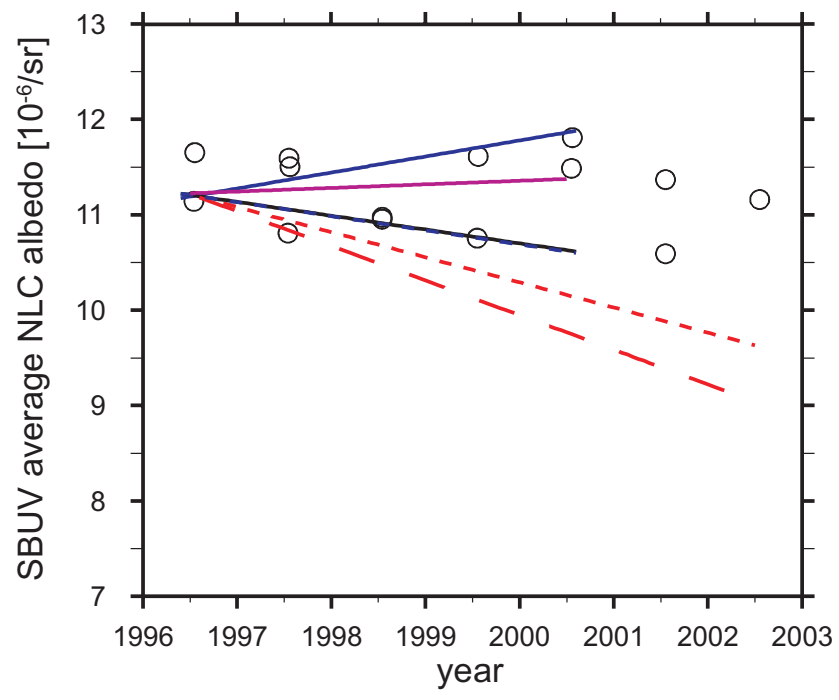

Fig. 8. SBUV observed albedo values $\mathrm{A}(252)$ (in black) as published by Thomas et al. (2004) and a linear fit through their data points from 1996 through 2000 (magenta line). Additional coloured lines indicate how the albedo A should have developed according to the COMMA/IAP model under the influence of observed changes in water vapour and solar Lyman $\alpha$ since 1996 (see text for details). This yields for the albedo A the solid blue line assuming the ALOMAR $\mathrm{H}_{2} \mathrm{O}$ microwave spectrometer observations in summer, the dashed blue line for the annually averaged ALOMAR microwave spectrometer observations, the short dashed red line for the annually averaged microwave spectrometer observations at $20^{\circ} \mathrm{N}$, and the long dashed red line for the annually averaged HALOE observations at $20^{\circ} \mathrm{N}$. In addition, a black line indicates the modelled decrease of NLC albedo under the influence of the observed increase in solar Lyman $\alpha$ flux.

\section{Discussion}

\subsection{Episodic changes and latitude dependence}

The fact is known for years (but sometimes overlooked) that in the upper mesosphere of all latitudes important episodic changes of water vapour occur, the causes for which have not yet been clearly identified. Long term observations of $\mathrm{H}_{2} \mathrm{O}$ in the upper mesosphere have become possible only since 1992 which means e.g. that the longest available record of genuine observations now covers barely a single cycle of solar activity. We obtain additional information on long term changes of Arctic upper mesosphere water vapour by studying the 22-year record of SBUV data on NLC brightness (see above). As of today, this record shows an increase of $+5.1 \%$ albedo/decade (see Fig. 6). If this increase is indeed caused by an increase of water vapour it would imply an increase of about $+4.5 \% \mathrm{H}_{2} \mathrm{O} /$ decade in the polar summer mesosphere regions. We note that this inferred rate of $\mathrm{H}_{2} \mathrm{O}$ increase is somewhat less than the $+6 \% \mathrm{H}_{2} \mathrm{O} /$ decade which were predicted by Thomas et al. (1989) for the long term increase of upper mesospheric water vapour. In addition, their prediction 


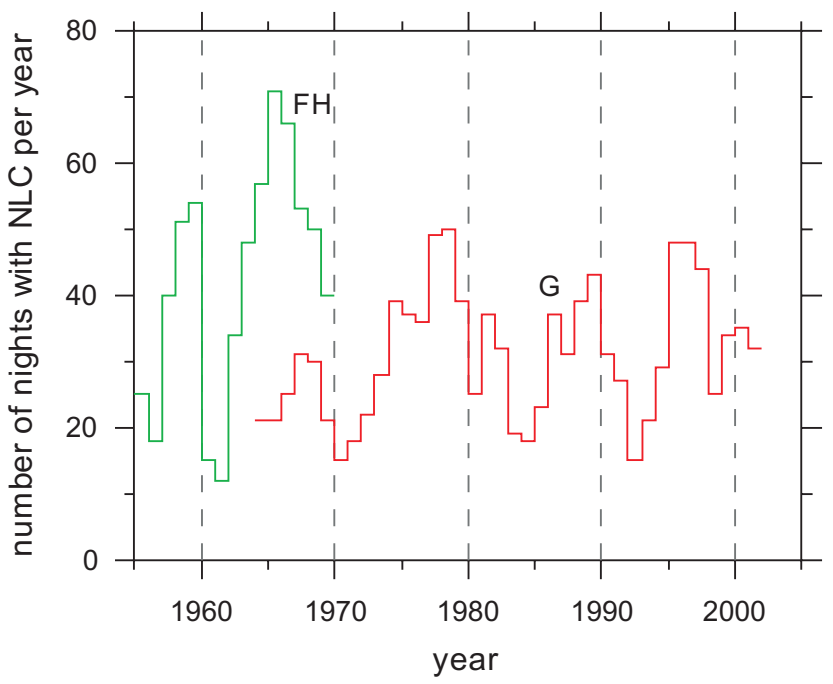

Fig. 9. Rate of occurrence of NLC from 1955 until 2001, measured by the number of nights per summer season in which NLC were observed visually from the ground. The green line represents data from Fogle and Haurwitz (1974), the red line represents those from Gadsden (2002).

was for a global (!) increase by this amount while we find evidence for such increase of $\mathrm{H}_{2} \mathrm{O}$ only in summer at the polar regions. Last, but not least, we must not discount the possibility that the observed NLC albedo increase has in fact little to do with an increase of the water vapour mixing ratio rather that it is caused predominantly by a so far undetected decrease of ambient temperature.

As short as the period of measurements of upper mesosphere water vapour is, it has become evident that the episodic changes of $\mathrm{H}_{2} \mathrm{O}$ are smaller at high latitudes than at mid and low latitudes. As the mixing ratio of water in the NLC region is strongly controlled by the vertical component of the background wind field, the observed changes of average $\mathrm{f}\left(\mathrm{H}_{2} \mathrm{O}\right)$ put new constraints on the dynamics included in GCMs. The latter have, as far as we know, not yet successfully simulated these episodic changes in general or even more specific their latitude dependence.

We emphasize the great importance of continued observations of the upper mesospheric water vapour in the Arctic! Only this special type of observation will help us to unravel some of the mysteries of NLC aeronomy.

6.2 Seasonal dependence of $\mathrm{f}\left(\mathrm{H}_{2} \mathrm{O}\right)$ and its episodic changes

A most interesting feature of the episodic changes in mesospheric water is the fact that they can become quite different in different seasons. We have shown here that the seasonal variation of episodic $\mathrm{H}_{2} \mathrm{O}$ changes is quite significant at the Arctic latitude of the ALOMAR observatory (see Table 2). More details of this seasonal variation as observed with the
ALOMAR microwave spectrometer will be published in a separate paper.

\subsection{Decadal variations of NLC occurrence rate}

The question of whether or not the occurrence rate of NLC has increased in the past century has been extensively discussed in the literature with quite different answers being given (e.g. Fogle and Haurwitz, 1974; Thomas et al., 1989; Gadsden, 1990, 1998, 2002; Kirkwood and Stebel, 2003; Romejko et al., 2003; von Zahn, 2003). Traditionally this occurrence rate has been expressed by the number of nights per summer season in which NLC were observed visually from the ground. Various records of this type have been published in the past, of which we show in particular those of Fogle and Haurwitz (1974) and of Gadsden (2002) in Fig. 9. A rapid increase of the NLC occurrence rate seems indicated by the data of Gadsden, in particular as published in his 1990 and 1998 papers. If we consider, however, the latest and supposedly best NLC record of Gadsden which is contained in his 2002 paper, then a significant increase of NLC occurrence rate can only be derived by including in the trend analysis the time period 1964 to 1969. During this period, the Gadsden (2002) data show a relative maximum of NLC occurrence rate which was much lower than the following three maxima of 1977/78, 1988/89, and 1995/96 (see Fig. 9). In this situation, Gadsden's low occurrence rates during the late 1960s predominate the outcome of any trend analysis of this rate which is based on just the Gadsden data.

There exists, however, another important record of NLC occurrence rate, namely that by Fogle and Haurwitz (1974). In their record, however, the time period 1964 to 1970 is characterized by an unusually strong maximum! Recent studies have led us to believe that a major cause for the very different numbers of NLC nights per year in the late1960s given by these two sources is the rather different geographical area over which their observations were collected. Gadsden refers to the work of Paton $(1968,1969)$ who collected $88 \%$ of his data from a rather small longitude sector (only $10^{\circ}$ wide). Fogle and Haurwitz present, however, a quasi-hemispherical sum of nights (see their list of references); Thus, Gadsden's statistics is effected much more by unfavourable weather conditions than that of Fogle and Haurwitz. Additional factors have been identified which might have contributed to the relative smallness of the 1967/68 maximum in the Gadsden statistics. Considering this background, neither data set is useful for a robust trend analysis of the occurrence rate of NLCs (von Zahn and Rendtel, 2004).

We now turn our attention to the observed dynamic range of the decadal variation in NLC occurrence rate. We define $\mathrm{F}$ to be the ratio of the maximum over minimum NLC occurrence rate throughout one decadal variation. This ratio has been studied by e.g. DeLand et al. (2003) using the record of long term changes in NLC parameters as recently derived from satellite SBUV observations. For the latitude 
Table 4. Observed ratios $\mathrm{F}$ and $\mathrm{R}$ for decadal NLC variations and $\beta$ in units of $\left[10^{-10} \mathrm{~m}^{-1} \mathrm{sr}^{-1}\right]$.

\begin{tabular}{cccc}
\hline & $\begin{array}{c}\text { SBUV observ. between } \\
50^{\circ} \mathrm{N} \text { and } 81^{\circ} \mathrm{N}\end{array}$ & $\begin{array}{c}\text { Ground-based visual observations } \\
\text { from North-West Europe }\end{array}$ & $\begin{array}{c}\text { Ground-based ALOMAR lidar observ. } \\
\text { at } 69^{\circ} \mathrm{N} \text { (this work) }\end{array}$ \\
\hline Occurrence rate & $\begin{array}{c}3.0<\mathrm{F}<6.2 \\
\text { (DeLand et al., 2003) } \\
\mathrm{R}=1.15\end{array}$ & $\begin{array}{c}\mathrm{F} \sim 3 \\
\text { (Gadsden, 2002) } \\
\text { (not available) }\end{array}$ & $\mathrm{F}=2.8$ for $\beta \geq 4$ \\
& (Shettle et al., 2004) & $\mathrm{F}=6.1$ for $\beta \geq 13$ \\
$\mathrm{R}=1.7$ for $\beta \geq 4$
\end{tabular}

band between $50^{\circ} \mathrm{N}$ and $81^{\circ} \mathrm{N}$, DeLand et al. (2003) derived ratios in the range $3.0<\mathrm{F}<6.2$ (see their Fig. 9). The Gadsden (2002) record of ground-based visual NLC observation from North-West Europe yields, as shown in Fig. 9, a ratio $\mathrm{F}$ of about $48 / 16=3$. A third set of alike data is becoming available through the climatological NLC observations by our lidar at the ALOMAR observatory $\left(69^{\circ} \mathrm{N}\right)$. Fiedler et al. (2003) have reported on results of these observations in the summers of 1997 through 2001. Now these lidar data cover the summers of 1997 through 2003, during which period at least one maximum and one minimum of NLC occurrence rate developed. From all our data on NLC with $\beta \geq 4 \times 10^{-10}$ and $\beta \geq 13 \times 10^{-10} \mathrm{~m}^{-1} \mathrm{sr}^{-1}$, we derive ratios $\mathrm{F}=2.8$ and 6.1 , respectively, for the one decadal cycle observed so far (Table 4). These F values fall in the same range as those found by DeLand et al. (2003) and Gadsden (2002). Considering that all three employed observations methods are totally different, the agreement of these results seems remarkable.

\subsection{Decadal variations of NLC albedo}

Now we turn to a consideration of the NLC albedo. We define $\mathrm{R}$ to be the ratio of the maximum over minimum annually averaged NLC albedo throughout one decadal period. NLC albedo variations have been studied e.g. by Shettle et al. (2004) and Thomas et al. (2004) using the same long-term set of SBUV observations as used by DeLand et al. (2003) for their analysis of the ratio $\mathrm{F}$ of occurrence rates. The decadal albedo variations exhibit, however, an unexpected feature. That is the fact that their ratio $\mathrm{R}$ turns out to be much smaller than the $\mathrm{F}$ ratios listed in Table 4. Shettle et al. (2004) derive a ratio $\mathrm{R}$ of maximum over minimum NLC albedo throughout the decadal variations of 1.15 only. The result, that decadal variations in NLC albedo are considerably smaller than those in occurrence rate, is also found in our ALOMAR lidar observations (Table 4). The large difference between decadal variations in NLC albedo and occurrence rate has not found much attention in the literature yet. We suggest that two effects might be responsible for this difference: (1) A strong decadal variation of the low latitude boundary of NLC and (2) an instrumentally caused truncation (diminution of the range) of observed albedo values by the SBUV experiment. We will comment on these two aspects in turn.
1. The large variation in occurrence rate probably reflects a strong correlation of the low latitude boundary of NLC with solar activity, the latter being a special type of decadal variation. The lower the solar activity is, the larger is the latitude band of NLC occurrence. If one imagines to observe at a fixed location at the lowest latitudes reached during solar minimum, then one would see nothing during solar maximum and hence get a large ratio of NLC occurrence at solar minimum over solar maximum. If one observes at, say, $80^{\circ} \mathrm{N}$, the NLC occurrence rate is high at any phase of the solar cycle. Hence, the ratio of NLC occurrence at solar minimum over solar maximum can never become very large. The analysis of DeLand et al. (2003) is based on satellite observations taken between $50^{\circ} \mathrm{N}$ and $81^{\circ} \mathrm{N}$. It thus includes a large area at mid latitudes that has only a small chance of NLC occurrence leading to a large $\mathrm{F}$ ratio. The sampling scenario is evidently different for the visually observed NLC events as collected by Gadsden (2002). 97\% of his events were reported from locations North of $51^{\circ} \mathrm{N}$ and the observed NLC are typically located even $4^{\circ}$ further North than the observer. Therefore, the low latitude boundary of the visual observations is at a latitude about $5^{\circ}$ higher than the $50^{\circ} \mathrm{N}$ of the SBUV observations. For the Arctic latitude of the ALOMAR observatory $\left(69^{\circ} \mathrm{N}\right)$ we might expect a continued decrease of the $\mathrm{F}$ ratio. This expectation comes true only marginally if we calculate the $\mathrm{F}$ ratio from all ALOMAR lidar observations with $\beta \geq 4 \times 10^{-10} \mathrm{~m}^{-1} \mathrm{sr}^{-1}$ (see Table 4). This may be due to the fact that the ALOMAR data encompass only one pair of maximum/minimum values or that the local time coverage of the two data sets is quite different (visual observations only during darkness versus lidar observations at all local times).

2. The smallness of albedo changes throughout the decadal variation as derived from the SBUV observations by Shettle et al. (2004) is difficult to understand against the background of rather large changes in occurrence rate. The published values for the ratios $\mathrm{F}$ and $\mathrm{R}$ imply that the latitudinal coverage of NLC can vary a great deal without a collateral variation in mean NLC albedo. We suggest that in the case of SBUV observations, their small value of $\mathrm{R}$ is at least in part due to the limited 
sensitivity and hence also dynamic range of these measurements. DeLand et al. (2003) require for the positive identification of a NLC its (residual) albedo to be $\mathrm{A}>7 \times 10^{-6}$ at $\beta=252 \mathrm{~nm}$. The same threshold is used by Shettle et al. (2004) for their analysis of albedo statistics. Their seasonally averaged albedo values fall, however, in the range of only 9 to $12 \times 10^{-6}$ (see their Fig. 1) and their mean value is thus only a factor 1.5 larger than the threshold value. This makes it likely, that the Shettle et al. (2004) average albedos and relative variations are strongly affected by the chosen threshold value.

If we apply this line of arguments to our ALOMAR lidar results, the numbers turn out as follows: In mid-summer and hence under sunlit conditions, our threshold value of volume backscatter coefficient $\beta$ for identification of a NLC is $\beta=4 \times 10^{-10} \mathrm{~m}^{-1} \mathrm{sr}^{-1}$, while our season-averaged $\beta$ values range from 9.5 to $16 \times 10^{-10} \mathrm{~m}^{-1} \mathrm{sr}^{-1}$. Hence, for our lidar observations the ratio of observed overall mean $\beta$ over the threshold value for $\beta$ is twice as large as that for the SBUV albedo observations. We suggest that this larger dynamical range of the lidar observations translates into a capability of the lidar to see dimmer NLCs than the SBUV instruments. This could account for the $\mathrm{F}$ value of the lidar observations $(\mathrm{F}=2.8)$ being smaller than that for the SBUV observations $(\mathrm{F} \sim 4.5)$. To support our point, we tentatively reduce our lidar dynamic range to cover only bright NLC having $\beta>13 \times 10^{-10} \mathrm{~m}^{-1} \mathrm{sr}^{-1}$ for which type of NLC the ALOMAR RMR lidar still has $124 \mathrm{~h}$ of observations. Those NLC yield a rather large ratio $\mathrm{F}=6.1$ (see Table 4).

\subsection{Unexpected stability of the Arctic summer mesosphere}

It becomes more and more evident that the Arctic summer mesosphere constitutes a region of unexpected stability against episodic or long term changes of a number of atmospheric parameters. This stability became first evident by the review of the mesopause temperatures in summer at high latitudes by von Zahn (1990). This attribute of unexpected stability was assigned to the thermal structure of the entire mesosphere in summer at high latitudes by Lübken (2000). For another phenomenon of the Arctic summer mesosphere, that is NLC, it was pointed out by Gadsden and Taylor (1994) and von Zahn and Berger (2003b) that their altitudes show an unexpected long term constancy. With the current study we now add the water vapour mixing ratio in the upper mesosphere to the ambient parameters which display an unexpected stability in the Arctic summer, at least over episodic time scales. We emphasize that we do not proclaim a perfect "zero-trend" for the water vapour in the Arctic summer mesosphere. Nonetheless, we consider the measurements of the ALOMAR microwave spectrometer to indicate a "near-zero episodic change" for the summer upper mesosphere mixing ratio $\mathrm{f}\left(\mathrm{H}_{2} \mathrm{O}\right)$ which is, to our knowledge, not predicted by any current global circulation model.
The one parameter which shows a significant longer term change is the NLC SBUV residual albedo A. From the material presented here we conclude that it seems unlikely that its long-term change is indeed controlled by a matching longterm change in upper mesospheric water vapour. The observed increase of A might well be caused by a rather gradual temperature decrease of the summer Arctic mesopause region, which is, however, so small, that it is still not directly measurable. An early discussion of this topic was given by Gadsden (1990).

\section{Conclusions}

(a) We have shown for the first time that episodic changes of water vapour in the upper mesosphere can exhibit strong seasonal differences. In particular, observations at an Arctic latitude since 1996 show the upper mesosphere water vapour to increase over time in summer, but to decrease considerably if averaged together with the other nine months of the year.

(b) No long-term observations of upper mesospheric water vapour exist which indicate a long-term increase of this parameter in the summer Arctic mesosphere. The cause for an observed long-term increase of $252 \mathrm{~nm}$ NLC albedo remains to be identified.

(c) Our COMMA/IAP model predicts a sensitivity of NLC brightness on the background water vapour at $80 \mathrm{~km}$ altitude as follows: For lidar backscatter observations at $532 \mathrm{~nm}$ our model predicts a $22 \%$ increase of $\beta$ for a $10 \%$ increase of $\mathrm{f}\left(\mathrm{H}_{2} \mathrm{O}\right)$, whereas for hemispheric SBUV observations at $252 \mathrm{~nm}$ it predicts only a $12 \%$ increase of the albedo A for the same increase in $\mathrm{f}\left(\mathrm{H}_{2} \mathrm{O}\right)$.

(d) Our COMMA/IAP model predicts the sensitivity of NLC brightness against variations in solar Lyman $\alpha$ flux via direct photolysis of $\mathrm{H}_{2} \mathrm{O}$ to be much less than hitherto presumed. This finding makes an understanding of the observed strong decadal variation of NLC occurrence probability even more difficult than before.

(e) We suggest that the large differences in observed NLC occurrence rates as published on the one hand by Fogle and Haurwitz (1974) and on the other hand by Gadsden (2002) are mostly due to a large difference in geographical area coverage used in these two studies.

(f) Finally, we conclude that the upper mesosphere reacts in the Arctic summer quite differently from the predictions of any current GCM model (including our own). Much remains to be learned in this particular region of our atmosphere. 
Acknowledgements. We thank L. Song and C. Jarchow for support in the analysis of the ALOMAR water vapour data. U. Berger acknowledges support through project DEKLIM (FörderKennzeichen 01LD0038) of the German Bundesministerium für Bildung und Forschung, Bonn, Germany.

Edited by: W. Ward

\section{References}

Berger, U. and von Zahn, U.: Icy particles in the summer mesopause region: Threedimensional modelling of their environment and two-dimensional modelling of their transport, J. Geophys. Res., 107, A11, 1366, doi:10.1029/2001JA000316, 2002 (The coloured figures of this paper were published in J. Geophys. Res., 108, A10, doi: 10.1029/2003JA010052, 2003).

Chu, X., Gardner, C. S., and Roble, R. G.: Lidar studies of interannual, seasonal, and diurnal variations of polar mesospheric clouds at the South pole, J. Geophys. Res., 108, D8, 8447, doi:10.1029/2002JD002524, 2003.

von Cossart, G., Fiedler, J., and von Zahn, U.: Size distributions of NLC particles as determined from 3-color observations of NLC by ground-based lidar, Geophys. Res. Lett., 26, 1513-1516, 1999.

DeLand, M. T., Shettle, E. P., Thomas, G. E., and Olivero, J. J.: Solar backscattered ultraviolet (SBUV) observations of polar mesospheric clouds (PMCs) over two solar cycles, J. Geophys. Res., 108, D8, 8445, doi:10.1029/2002JD002398, 2003.

Donahue, T. M., Guenther, B., and Blamont, J. E.: Noctilucent clouds in daytime: Circumpolar particulate layers near the summer mesopause, J. Atmos. Sci., 29, 1205-1209, 1972.

Fiedler, J., Baumgarten, G., and von Cossart, G.: Noctilucent clouds above ALOMAR between 1997 and 2001: Occurrence and properties, J. Geophys. Res., 108, D8, doi:10.1029/2002JD002419, 2003.

Fogle, B. and Haurwitz, B.: Long term variations in noctilucent cloud activity and their possible cause, in: Climatological Research, edited by: Fraedrich, K., Hantel, M., Claussen Korff, H., and Ruprecht, E., Bonner Meteorologische Abhandlungen, 7, 263-276, 1974.

Gadsden, M.: A secular change in noctilucent cloud occurrence, J. Atmos. Terr. Phys., 52, 247-251, 1990.

Gadsden, M.: The North-West Europe data on noctilucent clouds: a survey, J. Atmos. Solar-Terr. Phys., 60, 1163-1174, 1998.

Gadsden, M.: Statistics of the annual counts of nights on which NLCs were seen, Memoirs British Astron. Assoc., Vol. 45, Aurora Section, Papers given at the "Mesospheric Clouds 2002" meeting in Perth, Scotland, 19-22 August, 2002.

Gadsden, M. and Taylor, M.J.: Measurements of noctilucent cloud heights: a bench mark for changes in the mesosphere, J. Atmos. Solar-Terr. Phys., 56, 461-466, 1994.

Garcia, R. R.: Dynamics, radiation, and photochemistry in the mesosphere: implications for the formation of noctilucent clouds, J. Geophys. Res., 94, 14 605-14 615, 1989.

Hansen, G., Serwazi, M., and von Zahn, U.: First detection of a noctilucent cloud by lidar, Geophys. Res. Lett., 16, 1445-1448, 1989.

Hartogh, P. and Jarchow, C.: Groundbased detection of middle atmospheric water vapour, SPIE, 2586, 188-195, 1995.
Hartogh, P., Song, L., and Jarchow, C.: Annual and interannual variations of polar upper stratospheric and mesospheric water vapour, poster presented at Network for the Detection of Stratospheric Change (NDSC)-Meeting, Arcachon, France, 2427 September, 2001.

Hervig, M., McHugh, M., and Summers, M. E.: Water vapour enhancement in the polar summer mesosphere and its relationship to polar mesospheric clouds, Geophys. Res. Lett., 30, 20, 2041, doi:10.1029/2003GL018089, 2003

Hunten, D. M., Turco, R. P., and Toon, O. B.: Smoke and dust particles of meteoric origin in the mesosphere and stratosphere, J. Atmos. Sci., 37, 1342-1357, 1980.

Jensen, E. and Thomas, G. E.: A growth-sedimentation model of polar mesospheric clouds: comparison with SME measurements, J. Geophys. Res., 93, 2461-2473, 1988.

Kirkwood, S. and Stebel, K.: Influence of planetary waves on noctilucent cloud occurrence over NW Europe, J. Geophys. Res., 108, D8, 8440, doi:10.1029/2002JD002356, 2003.

Lübken, F.-J.: Nearly zero temperature trend in the polar summer mesosphere, Geophys. Res. Lett., 27, 3603-3606, 2000.

Marsh, D., Smith, A., and Noble, E.: Mesospheric ozone response to changes in water vapour, J. Geophys. Res., Vol. 108, No. D3, 4109, doi:10.1029/2002JD002705, 2003.

Mauersberger, K. and D. Krankowsky, Vapor pressure above ice at temperatures below $170 \mathrm{~K}$, Geophys. Res. Lett., 30, 3, 1121, doi:10.1029/2002GL016183, 2003.

McHugh, M., Hervig, M., Magill, B., Thompson, R. E., Remsberg, E., Wrotny, J., and Russell III, J.: Improved mesospheric temperature, water vapour and polar mesospheric cloud extinctions from HALOE, Geophys. Res., Lett., 30, 8, 1440, doi:10.1029/2002GL016859, 2003.

Merkel, A., Bailey, S., Thomas, G., Carstens, J., and Garcia, R.: Global characteristics of PMCs from six years of SNOE data, invited paper SA42B-01 presented at the 2003 Fall Meeting of the American Geophysical Union, San Francisco, December 2003.

Nedoluha, G. E., Bevilacqua, R. M., Gomez, R. M., Siskind, D. E., Hicks, B. C., Russell III, J. M., and Connor, B. J.: Increases in middle atmospheric water vapour as observed by the Halogen Occultation Experiment and the groundbased Water Vapour Millimeterwave Spectrometer from 1991 to 1997, J. Geophys. Res., 103, 3531-3543, 1998

Nedoluha, G. E., Bevilacqua, R. M., Gomez, R. M., Hicks, B. C., Russell III, J. M., and Connor, B. J.: An evaluation of trends in middle atmospheric water vapour as measured by HALOE, WVMS, and POAM, J. Geophys. Res., 108, D13, 4391, doi:10.1029/2002JD003332, 2003.

O’Neil, R. R., Richards, E., Humphrey, C. H., Stair, A. T., and Gardner, M. E.: MSX: Infrared emission from polar mesospheric clouds, paper SA31B presented at the 2001 Spring Meeting of the AGU, Boston, MA, USA, 2001.

Paton, J.: Noctilucent clouds over western Europe during 1967, Meteorol. Magazine, 97, 174-176, 1968.

Paton, J.: Noctilucent clouds over western Europe during 1968, Meteorol. Magazine, 98, 219-222, 1969.

Randel, W. J., Wu, F., Russell III, J. M., Zawodny, J. M., and Nash, $\mathrm{J} .:$ Interannual changes in stratospheric constituents and global circulation derived from satellite data, in Atmospheric Science across the Stratopause, Geophysical Monograph, 123, 271-285, 2000 
Rapp, M., Lübken, F.J., Müllemann, A., Thomas, G. E., and Jensen, E. J.: Small scale temperature variations in the vicinity of NLC: Experimental and model results, J. Geophys. Res., 107, D19, 4392, doi:10.1029/2001JD001241, 2002.

Romejko, V. A., Dalin, P. A., and Pertsev, N. N.: Forty years of noctilucent cloud observations near Moscow: Database and simple statistics, J. Geophys. Res., 108, D8, doi: 10.1029/2002JD002364, 2003.

Seele, C. and Hartogh, P.: Water vapour of the polar middle atmosphere: Annual variation and summer mesosphere conditions as observed by groundbased microwave spectroscopy, Geophys. Res. Lett., 26, 1517-1520, 1999.

Shettle, E. P., DeLand, M. T., Thomas, G. E., and Olivero, J. J.: Multi-decadal satellite observations of PMCs with SBUV and SBUV/2, Memoirs British Astron. Assoc., Vol. 45, Aurora Section, Proc. "Mesospheric Clouds 2002" meeting, Perth, Scotland, 2002.

Shettle, E. P., DeLand, M. T., Thomas, G. E., and Olivero, J. J.: Variations in the average brightness of polar mesospheric clouds from twenty-four years of SBUV measurements, Memoirs British Astron. Assoc., Proc. "Mesospheric Clouds 2003" workshop, Galway, Ireland, in press, 2004.

Sonnemann, G. R. and Grygalashvyly, M.: Solar influence on mesospheric water vapour with impact on NLCs, J. Atmos. Solar Terr. Phys., in press, 2004.

Thayer, J., Rapp, M., Gerrard, A., Gudmundsson, E., and Kane, T.: Gravity wave influences on Arctic mesospheric clouds as determined by the Sondrestrom, Greenland, Rayleigh lidar, J. Geophys. Res., 108, D8, doi:10.1029/2002JD002363, 2003.

Thomas, G. E., Olivero, J. J., Jensen, E. J., Schroeder, W., and Toon, O. B.: Relation between increasing methane and the presence of ice clouds at the mesopause, Nature, 338, 490-492, 1989.

Thomas, G. E., McPeters, R. D., and Jensen, E. J.: Satellite observations of polar mesospheric clouds by the solar backscattered ultraviolet spectral radiometer: Evidence of a solar cycle dependence, J. Geophys. Res., 96, 927-939, 1991.
Thomas, G. E., Rapp, M., Olivero, J. J., Shettle, E. P., and DeLand, M.: Long-term variability in the brightness and occurrence frequency of mesospheric clouds explained by water vapour changes, Memoirs British Astron. Assoc., Aurora Section, Proc. of the „Mesospheric Clouds 2003” meeting, Galway, Ireland, in press, 2004.

Woods, T. N., Tobiska, W. K., Rottman, G. J., and Worden, J. R.: Improved solar Lyman $\alpha$ irradiance modelling from 1947 through 1999 based on UARS observations, J. Geophys. Res., 105, 27 195-27 215, 2000.

von Zahn, U.: Temperature and altitude of the polar mesopause in summer, in: COSPAR International Reference Atmosphere: 1986; Part 2: Middle Atmosphere Models, edited by: Rees, D., Barnett, J. J., and Labitzke, K., Pergamon Press, 223-231, 1990. von Zahn, U.: Are noctilucent clouds truly a "miner's canary" for global change? EOS, 84, 28, 261-268, 15 July, 2003.

von Zahn, U. and Berger, U.: Persistent ice cloud in the midsummer upper mesosphere at high latitudes: Three-dimensional modelling and cloud interactions with the ambient water vapour, J. Geophys. Res., 108, D8, doi:10.1029/2002JD002409, 2003a.

von Zahn, U. and Berger, U.: The altitude of noctilucent clouds: Groundbased observations and their interpretation through numerical modelling, in: Proc. 16th ESA Symp. on European Rocket and Balloon Programmes and Related Research, edited by: Warmbein, B., ESA SP-530, 295-301, 2003b.

von Zahn, U. and J. Rendtel: Long-term records of visual observations of the occurrence rate of NLC: Can they be used to derive a significant trend of this rate?, paper presented at the "International Workshop on Layered Phenomena in the Mesopause Region”, 14-17 Sept. 2004, Cambridge, UK, 2004.

von Zahn, U., von Cossart, G., Fiedler, J., Fricke, K. H., Nelke, G., Baumgarten, G., Rees, D., Hauchecorne, A., and Adolfsen, K.: The ALOMAR Rayleigh/Mie/Raman lidar: objectives, configuration, and performance, Ann. Geophys., 18, 815-833, 2000, SRef-ID: 1432-0576/ag/2000-18-815. 